\title{
Magnetic field configurational study on A Helicon-Based Plasma Source for Future Neutral Beam Systems
}

Kamal M. Ahmed ${ }^{1}$, Riccardo Agnello ${ }^{2}$, Stéphane Béchu ${ }^{3}$, Gilles Cartry ${ }^{4}$, H.P.L de Esch ${ }^{5}$, Ivo Furno $^{2}$, Philippe Guittienne ${ }^{6}$, Alan Howling ${ }^{2}$, Rémy Jacquier ${ }^{2}$, Iaroslav Morgal ${ }^{4}$, Nader Sadeghi ${ }^{7}$, Alain Simonin ${ }^{5}$

1 Plasma and Nuclear Fusion Dept.- Nuclear Research Center- Atomic Energy Authority, Cairo, Egypt.

2 EPFL, Swiss Plasma Center (SPC), CH-1015 Lausanne, Switzerland

3 LPSC, Université Grenoble-Alpes, CNRS/IN2P3, F-38026 Grenoble, France

4 Aix-Marseille Université, CNRS, PIIM, UMR 7345, F-13013 Marseille, France.

5 CEA, IRFM, F-13108, Saint-Paul-Lez-Durance, France.

6 Helyssen, Route de la Louche 31, CH-1092 Belmont-sur-Lausanne, Switzerland.

7 LIPhy (UMR 5588) \& LTM (UMR 5129) Univ. Grenoble-Alpes \& CNRS, Grenoble, France

\begin{abstract}
A helicon-based plasma source is under development and exploration at CEA-IRFM to produce an efficient and dense magnetized plasma column. The final objective of this development is the extraction and acceleration of a blade-like negative ion beam in view of future neutral beam injector systems for fusion reactors. The extraction of a negative ion beam from a magnetized plasma column requires a specific topology of the magnetic confinement, which significantly impacts the plasma parameters and wave propagation along the column. The magnetic confinement under investigation is based on water-cooled internal coils implemented under vacuum along the source (column) axis; these coils are supplied with a high DC current $(\sim 1000$ A), providing the axial magnetic field $(B / / \sim 10 \mathrm{mT})$. Different diagnostics developed in academic laboratories, such as 3D B-dot probes, optical emission spectroscopy and Langmuir probes, have been used for plasma characterization. The paper reports the experimental results obtained under different operating conditions of this particular magnetic confinement.
\end{abstract}

Keywords: NBI, Helicon plasma source, B-dot measurements, Fulcher- $\alpha$, gas temperature.

\section{Introduction}

Explorative R\&D aimed at increasing the performance of the neutral beam injectors (NBI) for future fusion reactors is performed by CEA, EPFL and academic laboratories in France.

The new injector concept is based on $\mathrm{D}^{-}$beam neutralization by photo-detachment [1-3], in which a high-power photon flux $(\sim 3 \mathrm{MW})$ generated within a Fabry-Perot cavity will cross and partially photo-detach a high-current $1 \mathrm{MeV}$ negative ion $\left(\mathrm{D}^{-}\right)$beam sheet leading to more than $\sim 90 \%$ beam neutralization. The beam-line aspect ratio (high and thin) is specifically designed to maximize the overlap of the energetic $\mathrm{D}^{-}$beam sheet $\left(\sim 10 \mathrm{~A} \mathrm{D}^{-}, 3 \mathrm{~m}\right.$ height and $1 \mathrm{~cm}$ width) by the intra-cavity photon beam (see Fig. 1). Such blade-like topology breaks with conventional ion sources (ITER type) and accelerators. For this purpose, CEA is studying a new negative ion source concept based on a magnetized plasma column (B// to the source vertical axis), in which the plasma is generated by a resonant helicon antenna developed at EPFL [4-5].

Helicon plasma drivers are commonly used to provide dense plasma columns over a wide range of magnetic field intensities (10-100 mT), and the axial magnetic field can be provided either by permanent magnets [6-7] or external electromagnets [8-9]. Helicons differ from the inductive coupled plasma (ICP) because the electrons ionize along the magnetic field over a relatively long distance (more than 1 metre) [10].

Helicon plasma drivers have numerous applications in industry (material/surface treatments [1112]), space propulsion [13-15], electric propulsion [16-17], accelerators [18], and negative ion sources [1-3, 19-23].

Their application in the field of large negative ion sources for fusion could benefit from substantial advantages, such as a higher plasma density with low RF power and a lower operating source pressure compared to that of the conventional ICP drivers. On the ITER ion source, a set of eight ICP drivers 
with $100 \mathrm{~kW}$ of $\mathrm{RF}$ power each are required to illuminate the large accelerator grid $\left(0.8 \mathrm{~m}^{2}\right)$ and produce the required $\mathrm{D}^{-}$current density $\left(\mathrm{J}_{\mathrm{D}^{-}}-250 \mathrm{~A} / \mathrm{m}^{2}\right)[24-25]$.

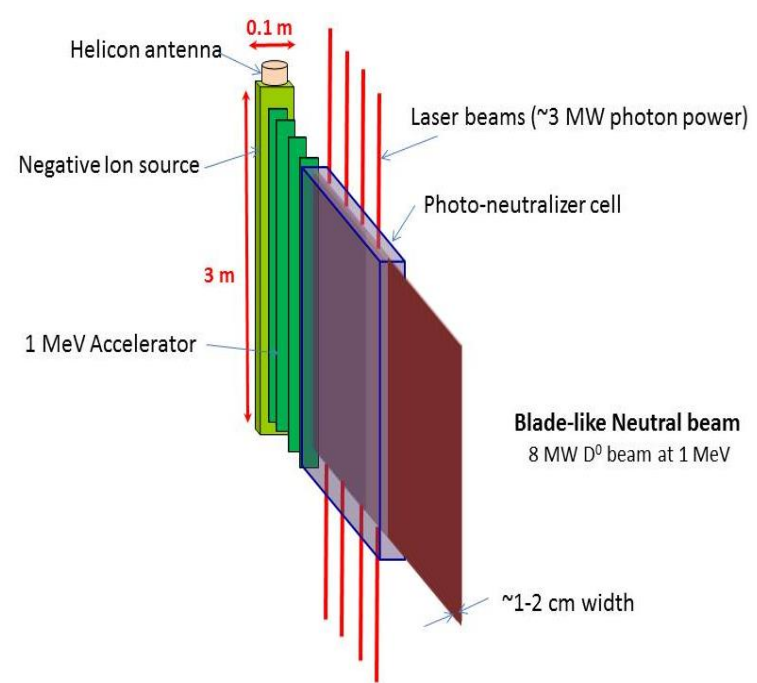

Figure 1: Sketch of the photo-neutralization based NBI system

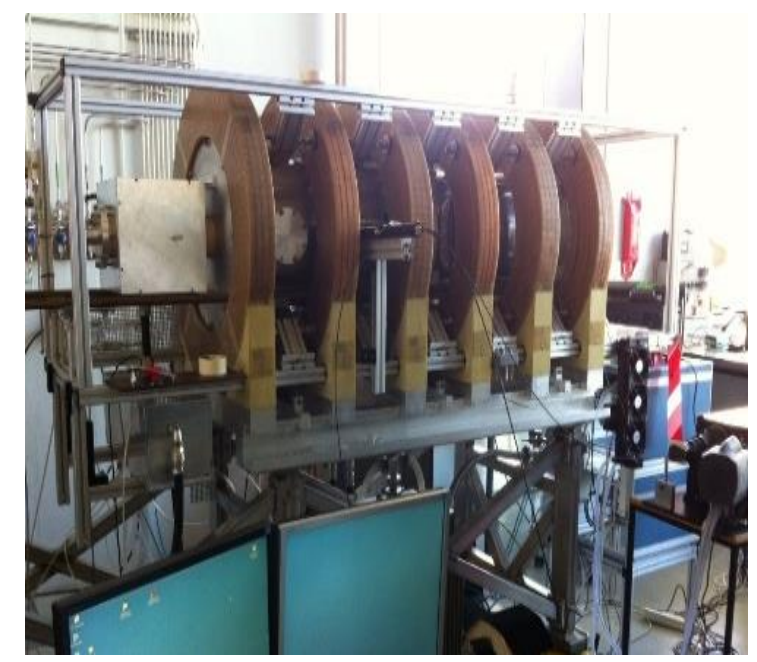

Figure 2: Photograph of the RAID testbed at EPFL [4].

To meet the required specifications of a negative ion source for fusion, EPFL has developed a novel helicon antenna (called the "bird-cage" antenna) [5]. This new antenna on the RAID testbed generates a stable hydrogen (and deuterium) plasma column 1 metre long with a central density of hydrogen, $n_{e}>10^{18} \mathrm{~m}^{-3}$ uniformly distributed along the column axis. The helicon can operate at a low magnetic field $(\sim 10 \mathrm{mT})$ and low operating pressure $\left(\mathrm{p}_{\mathrm{s}}<0.2-0.3 \mathrm{~Pa}\right)$ [1-3]. A copy of this antenna has been manufactured and implanted on the IRFM ion source testbed to address negative ion beam extraction. The goal of this source is to produce and extract negative ions along the edge of the long plasma column and to characterize the blade-like ion beam at low energy $(\sim 30 \mathrm{keV})$.

On RAID [4], the axial magnetic field is provided by a set of large 6 Helmholtz coils $(\sim 60 \mathrm{~cm}$ diameter) implanted outside of the vacuum tank (see Fig. 2 ), the axial magnetic field (B//) is uniform, and its transverse (radial) component $(\mathrm{B} \perp)$ is negligible (the coil surrounding the antenna has an opposite polarity with respect to the other five, resulting non-homogenous magnetic field in the antenna position). This magnetic arrangement is ideal for studying the physics of helicon plasma columns. However, the configuration does not allow the implantation of an NBI-relevant accelerator along the edge of the plasma column except between the coils.

The first step of the R\&D at IRFM is to study and characterize the helicon plasma column under different magnetic-confinement configurations that must comply with both the constraints and requirements of the helicon antenna and the implantation of an accelerator on the plasma edge; two confinements (lateral and internal coils) have been considered and experimented on up to now.

The magnetic field of the first configuration was generated by a DC current flowing in two lateral electric coils sitting on both sides of the source [2]. These coils were wound around an iron rectangular frame (see Fig 3a). This arrangement provided a field intensity of $10 \mathrm{mT}$ in the source volume for a coil current of $\sim 300 \mathrm{~A}$. The main advantage of this magnetic arrangement is the free access on the front of the plasma column to implement the accelerator.

The 3D simulations of this magnetic setup indicate that the axial component $(\mathrm{B} / /)$ is uniformly distributed over the full source volume $\left(\mathrm{B}_{/ /} \sim 10 \mathrm{mT}\right)$, but the transverse component $(\mathrm{B} \perp)$ is not negligible. $\mathrm{B} \perp$ is effectively null along the central axis, but it increases up to $2 \mathrm{mT}$ towards the lateral coils, and on the front and back of the source leading to a "ballooning" effect (see Fig. 3b).

Experiments have indicated that the helicon plasma column is highly-sensitive to this transverse magnetic field; the electrons are fully magnetized, and they follow the magnetic field lines. The plasma column is laterally compressed and expands (on the back and front) at its mid-height. 
An experiment involving Langmuir probes implanted on the source front confirmed the ballooning effect of the plasma shape on the front and back of the source: the measured plasma density is low $\left(\mathrm{n}_{\mathrm{e}} \sim 1-5 \times 10^{16} \mathrm{~m}^{-3}\right)$, and the plasma is not uniformly distributed along the extraction surface. Moreover, Langmuir probes have also revealed that the electron temperature is abnormally high with respect to RAID $\left(T_{e} \sim 7 \mathrm{eV}\right)$ on the plasma edge ( $\mathrm{r} \sim 5 \mathrm{~cm}$ from the plasma column axis) [26].

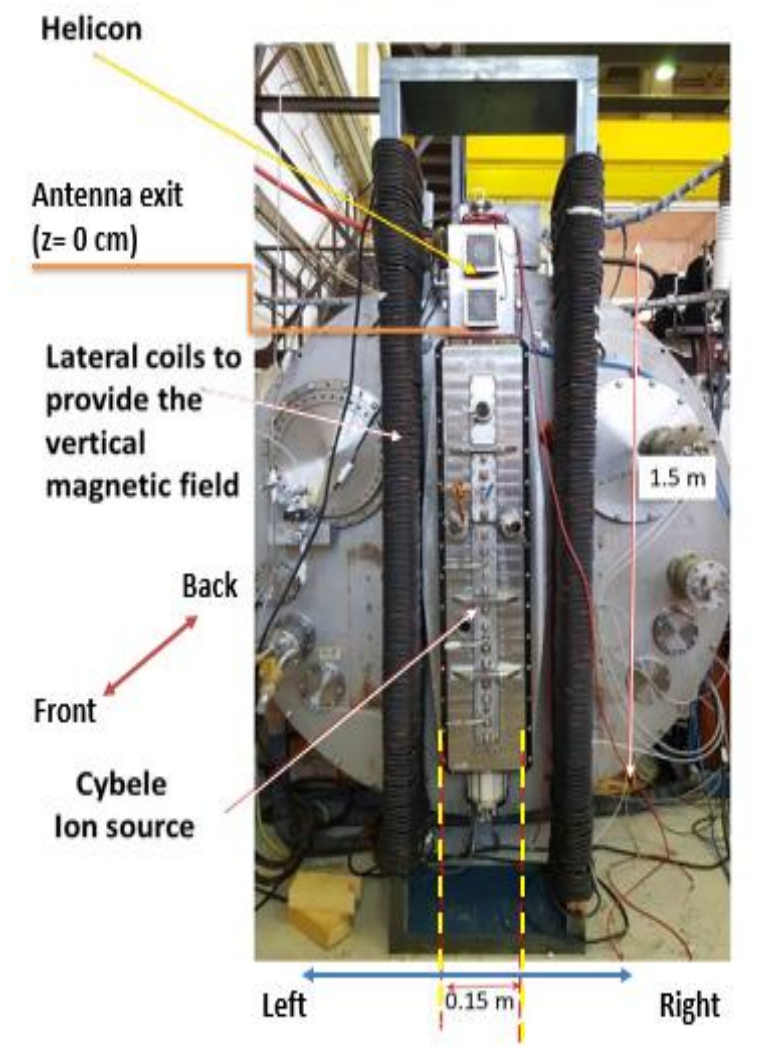

(a)

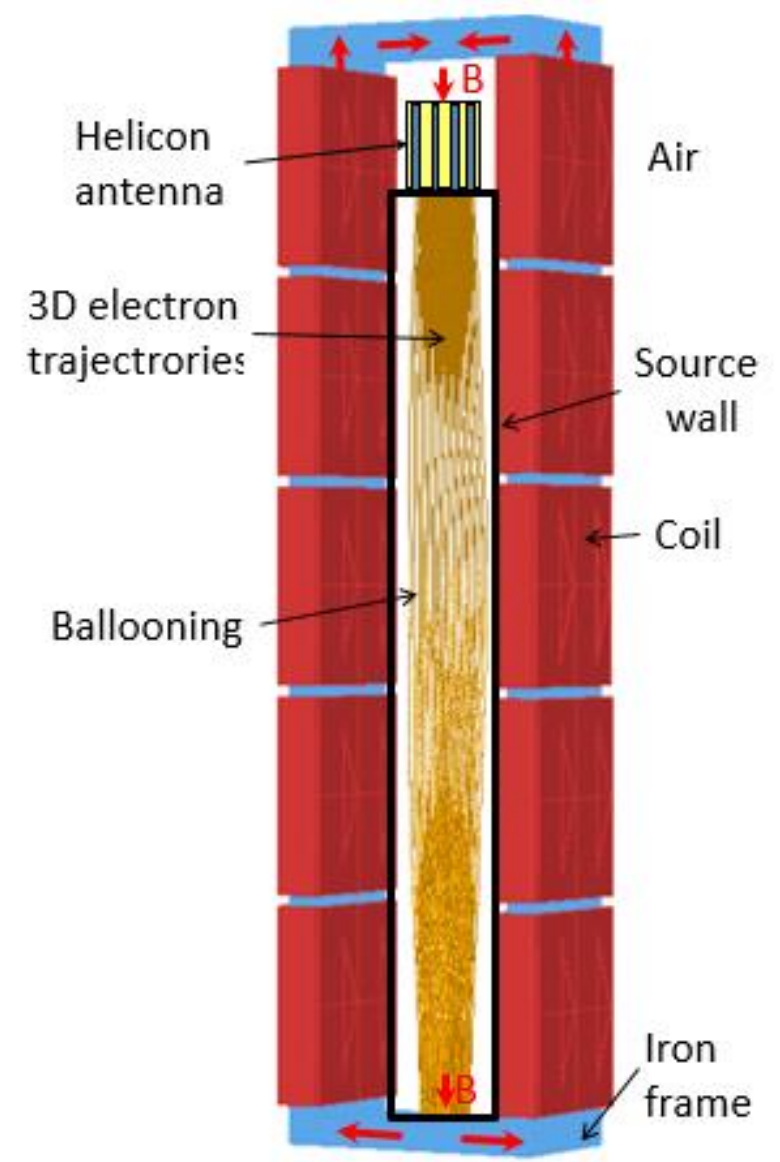

(b)

Figure 3: (a) Back-view of the Cybele source with the external lateral coil sitting on both sides;

(b) Simulation of the 3D electron trajectories (electron energy $10 \mathrm{eV}$ ) with the lateral coils confinement.

On the RAID testbed, the plasma density is more than one order of magnitude compared with the abovementioned value, and the electron temperature is lower than $2 \mathrm{eV}$ at the plasma edge $(5 \mathrm{~cm}$ from the plasma centre) [4].

In conclusion, this magnetic confinement has poor efficiency, and induces a convex plasma shape that is not compatible with the implantation of a long accelerator on the front of the plasma column.

This paper describes the experimental results obtained with a magnetic confinement more compatible with helicon plasmas and accelerator implementation; the arrangement is based on a set of cylindrical coils implanted under vacuum within the source volume at the exit of the helicon antenna. The paper reports the experimental results obtained from this helicon plasma column via different diagnostics - Langmuir probes, B-dot probes and spectroscopy - as a function of the operating conditions (magnetic field, gas pressure, electrode polarization, etc.).

\section{Description of the IRFM experimental setup.}

The IRFM ion source is a linear magnetized plasma source (see Fig. 3a) used for the production and study of negative ion beams. The source dimensions $(120 \mathrm{~cm}$ height, $15 \mathrm{~cm}$ width and $20 \mathrm{~cm}$ depth) are specifically adapted to explore blade-like $\mathrm{H}^{-}$beam extraction. A helicon antenna is installed 
on the top of the source (see Fig. 3a) where the ions and electrons produced in the antenna can diffuse along the magnetic field lines in the main vessel, and the accelerator is implanted in the vacuum tank on the source front (see Fig. 4). The first accelerator electrode (usually called the plasma grid; PG in negative ion sources), is a vertical slit in contact with the plasma column and placed at its edge, $7 \mathrm{~cm}$ away from the source (helicon) axis.

To limit destruction of negative ions on the plasma edge, the electron temperature must be lower than $2 \mathrm{eV}$ near the PG. Negative ions are produced in the plasma volume by dissociative attachment and/or by electron capture of backscattered $\mathrm{H}^{\circ}$ (and $\mathrm{H}^{+}$) on the $\mathrm{PG}$ cesiated surface.

The helicon is a resonant "birdcage" antenna [5] supplied by an RF power supply (power up to 10 $\mathrm{kW}$ at frequency of $13.56 \mathrm{MHz}$ ) via the matching box.

The helicon antenna is in the air (see Fig. 4), and surrounded by an external solenoid coil to provide the magnetic field within the antenna region and to excite the plasma downstream to the source. In the source volume, eleven internal coils spaced by $10 \mathrm{~cm}$ have been implanted (see Fig. 4 and 5); each coil is a $6 \mathrm{~mm}$ diameter water-cooled copper tube (see Fig. 5), consisting of a single winding measuring $10 \mathrm{~cm}$ in diameter. These eleven coils are connected in series, and are supplied with a DC electrical current ( $1000 \mathrm{~A})$; the voltage drop between the first (coil No. 1) and last coils (coil No. $11)$ is $11 \mathrm{~V}$. This coil arrangement allows for blade extraction through the gap between two consecutive coils.

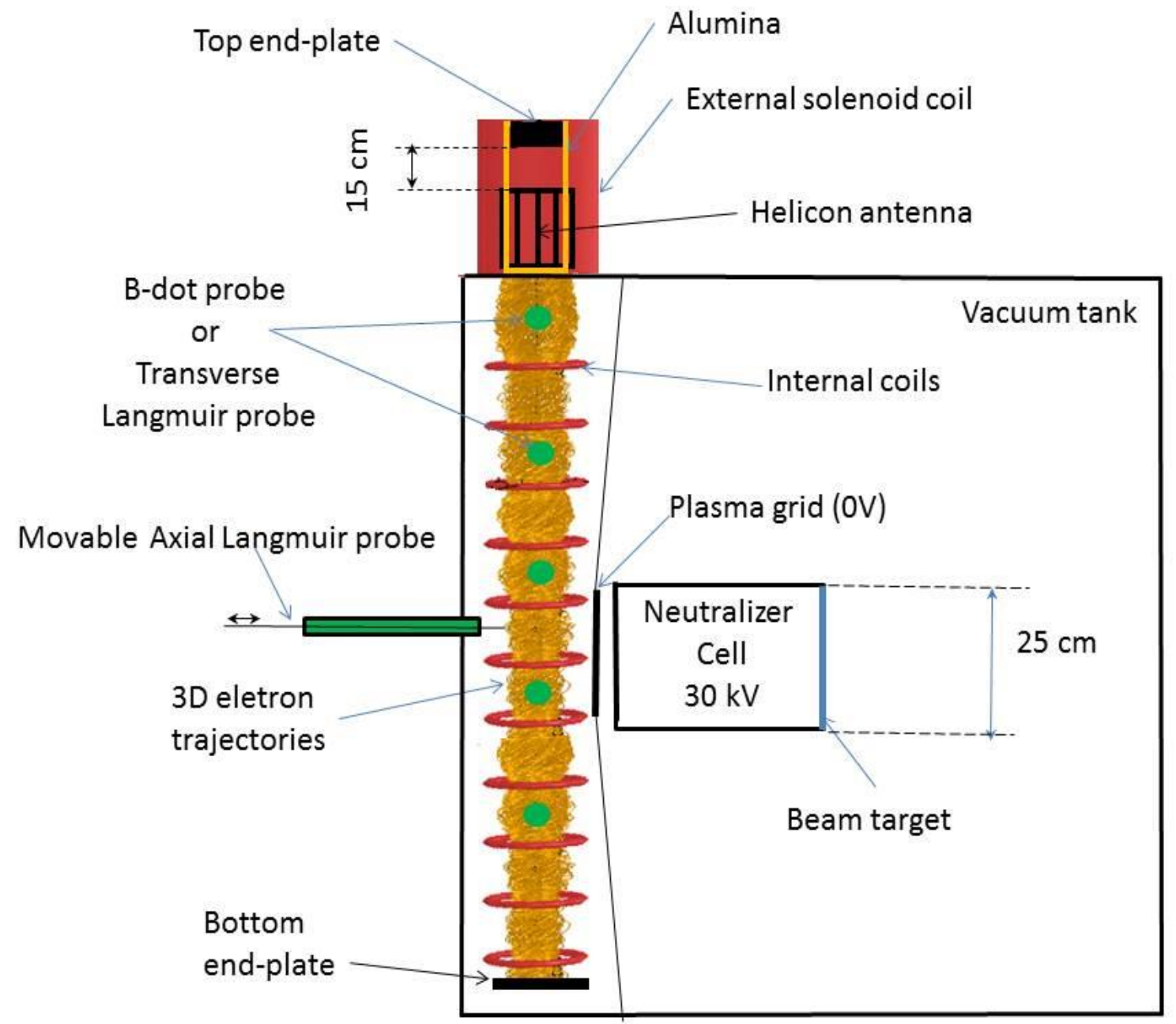

Figure 4: Setup of the IRFM testbed. This figure shows a 3D simulation of the electron trajectories in the source volume with the internal coils; the prototype plasma grid ( $25 \mathrm{~cm}$ height $)$ at mid-height of the plasma column, which is at the ground (source potential); and the accelerating grid ( $2 \mathrm{~cm}$ downstream), which is polarized at $30 \mathrm{kV}$ for beam extraction formation. The $\mathrm{H}^{-}$beam can be neutralized by a gas target and analyzed on a calorimeter (beam target). 


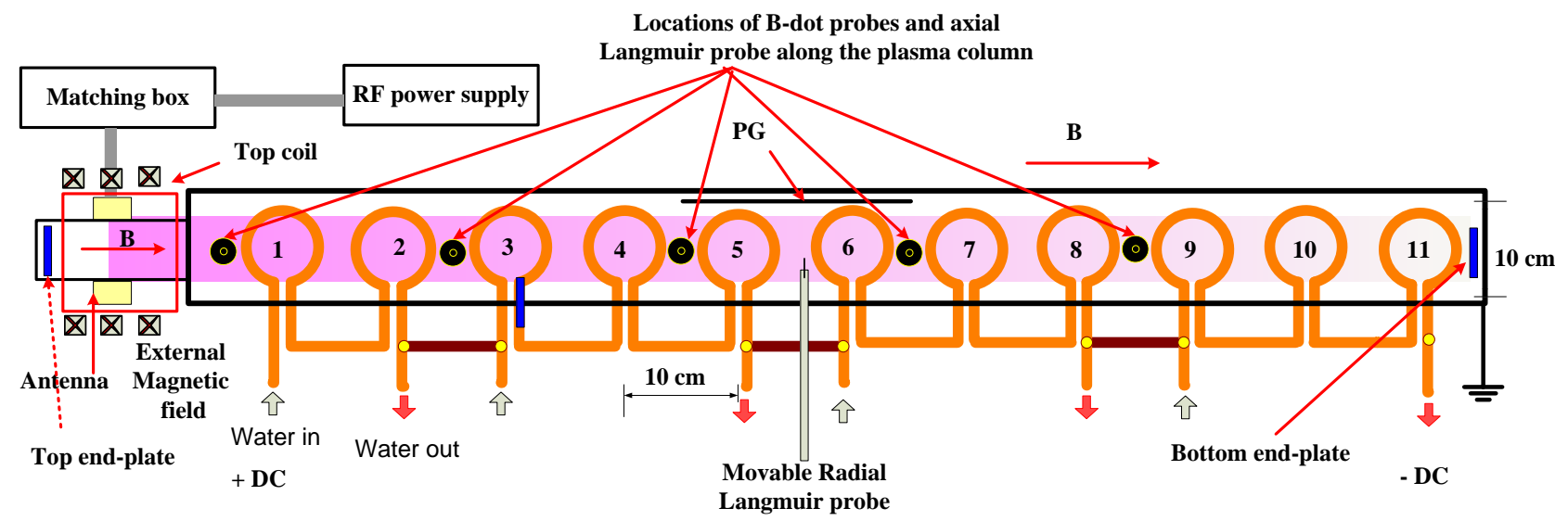

Figure 5: A schematic of the internal coil Helicon plasma source.

At the two extremities of the plasma column, metal plates have been implanted to collect the plasma particles. These plates (called the "Top and Bottom end-plates") can be independently biased, grounded or floating. The top end-plate is situated $15 \mathrm{~cm}$ above the top of the antenna (see Fig. 4).

The 3D Opera code [27] is used to simulate the 3D magnetic field distribution and the 3D collisionless (without plasma) electron trajectories.

Figure 4 depicts the trajectories of $5 \mathrm{eV}$ electrons emitted at the helicon exit. It is noted that the electrons are confined along the column; a significant modulation of the magnetic field induces a compression of the trajectories within each coil and a lateral expansion in-between.

The gas injection system consists of a set of two gas valves; the first one is used for the Ar gaspuff essential to ignite the plasma (pressure approximately $0.08 \mathrm{~Pa}$ ), which lasts for approximately 5 $\mathrm{s}$ at the beginning of the discharge. The second valve allows for the injection of hydrogen gas. The gas pressure can be set from $\mathrm{p} \sim 0.15$ to $0.5 \mathrm{~Pa}$. In addition, to observe the visible light emitted from the plasma, several windows have been installed on the source back flange and on the lateral side. A typical discharge lasts approximately $60 \mathrm{~s}$, and the shots have a relatively high repetition rate (20 25 pulses per hour).

\section{The Langmuir probes diagnostic:}

To measure plasma parameters such as the plasma density and temperature, Langmuir probes are used.

To characterize the plasma column in the vertical direction, several Langmuir probes (diameter $1.2 \mathrm{~mm}$, length $8 \mathrm{~mm}$ ) are inserted in the planes between the internal coils at different axial distances (from $20 \mathrm{~cm}$ up to $100 \mathrm{~cm}$ ) from the helicon antenna exit $(0 \mathrm{~cm}$ as shown in Fig. 3 ).

The transverse (radial) plasma parameters are measured via the movement of a Langmuir probe during a shot from the front wall (opposite wall to the PG) to the plasma grid as shown in figure 5.

These probes are polarized by a $10 \mathrm{~Hz}$ sawtooth voltage signal between $-100 \mathrm{~V}$ and $60 \mathrm{~V}$. The probe current is measured using a series resistor $(15 \Omega)$. A low pass filter (cut-off frequency $\sim 1 \mathrm{MHz}$ ) is connected between the output of the Langmuir probe and the data acquisition system to remove the RF components and their harmonics from the current signal.

Figure 6 shows an example of the current collected by the probe (recorded on the acquisition system) as a function of time for a typical $3 \mathrm{~kW}$ RF plasma shot. The plasma sequence is five regions as follows: firstly, injection of $0.08 \mathrm{~Pa}$ Ar gas-puff (Fig 6-region A) to ignite the plasma with $500 \mathrm{~W}$ RF power. Regions B-C-D are: injection of hydrogen and termination of argon with gradual increase in the RF power up to $3 \mathrm{~kW}$. Finally, region $\mathrm{E}$ is a steady-state hydrogen plasma at $3 \mathrm{~kW}$ (filling pressure; $0.3 \mathrm{~Pa}$ ) for data analysis.

The expanded time scale of the figure shows the current variation with the probe voltage sweep from $-100 \mathrm{~V}$ (ion saturation current) to $60 \mathrm{~V}$ (electron saturation current).

The probe signal is clean, and does not exhibit any fluctuation in the electron saturation region indicating the absence of plasma instability under this low B-field (10 mT). 

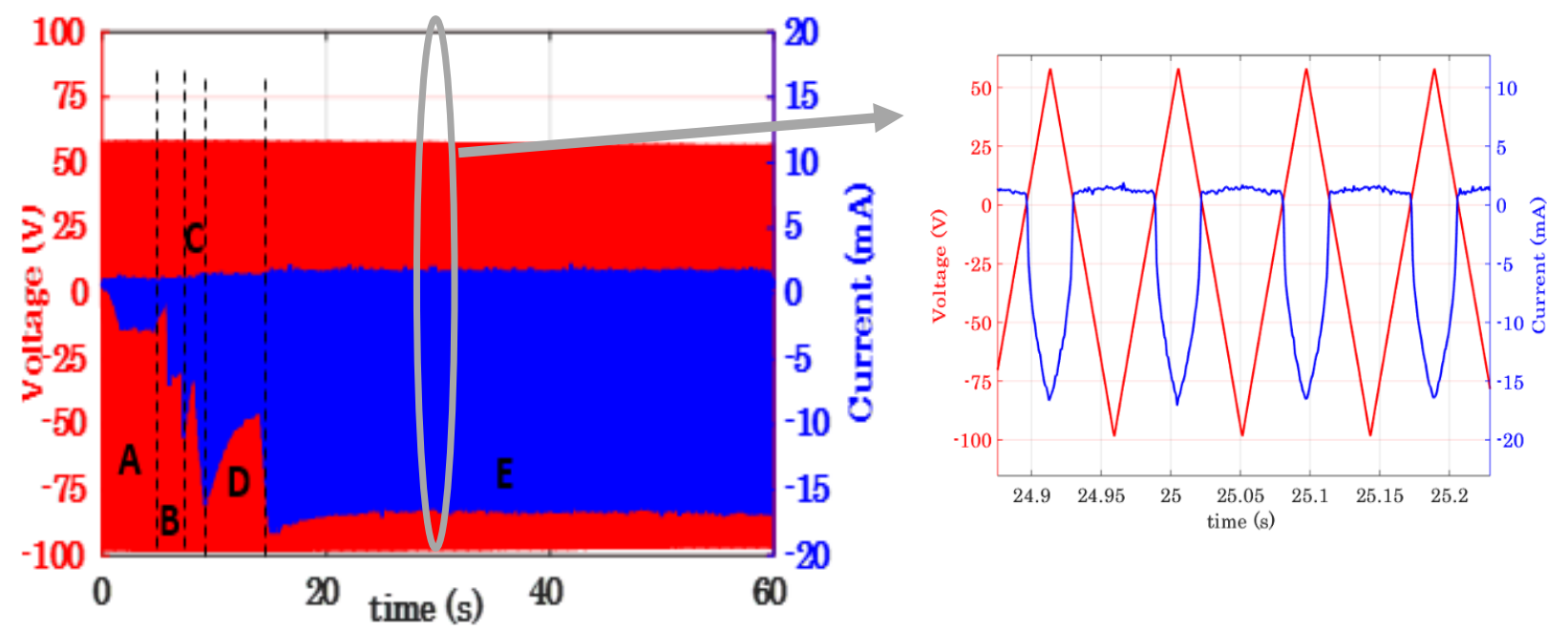

Figure 6: Sample of the voltage sweep and collected current obtained by Langmuir probe where:

Left: acquisition during one discharge, Region A: injection of Ar gas puffing, Regions B-C-D: injection of $\mathrm{H}$ and termination of Ar with gradual increase in the RF power up to $3 \mathrm{~kW}$, Region $\mathrm{E}$ : steady-state hydrogen plasma at $3 \mathrm{~kW}$.

Right: expanded time scale with a $10 \mathrm{mT}$ magnetic field, $3 \mathrm{~kW}$ of RF power and $0.3 \mathrm{~Pa}$ hydrogen in the floating configuration.

\section{The B-dot probe diagnostic [28]:}

This diagnostic has been developed and manufactured by EPFL [28] to characterize the RF wave in the IRFM ion source. The B-dot probe is a 3D probe that consists of three inductive pick-ups coils wrapped around a cubic ceramic head $\left(5 \times 5 \times 5 \mathrm{~mm}^{3}\right)$.

This head is fixed on a rod made of stainless non-magnetic steel, which acts as a Faraday shield for the cables. Then, the head is covered by a ceramic tube $(13 \mathrm{~cm}$ long) to protect the probe from the plasma bombardment. This rod can mechanically shift and tilt the probe within the plasma, as shown in figure 7. The radial profile of the magnetic field is measured via the movement of a B-dot probe radially (in direction parallel to the PG) from the left wall to the right wall while the axial profile is measured at the center of the plasma column $(\mathrm{r}=0)$ at different axial distance from the helicon antenna $(10,30,50,70$ and $90 \mathrm{~cm})$ as shown in figure 5 . Figure 8 shows a signal of the magnetic field obtained by the B-dot probe in 3D in the IRFM source. The fast Fourier transform (FFT) of these three signals shows that; the main frequency is $13.56 \mathrm{MHz}$, the upper $2^{\text {nd }}, 3^{\text {rd }}$ harmonics are negligible, implies non-linearity in plasma.

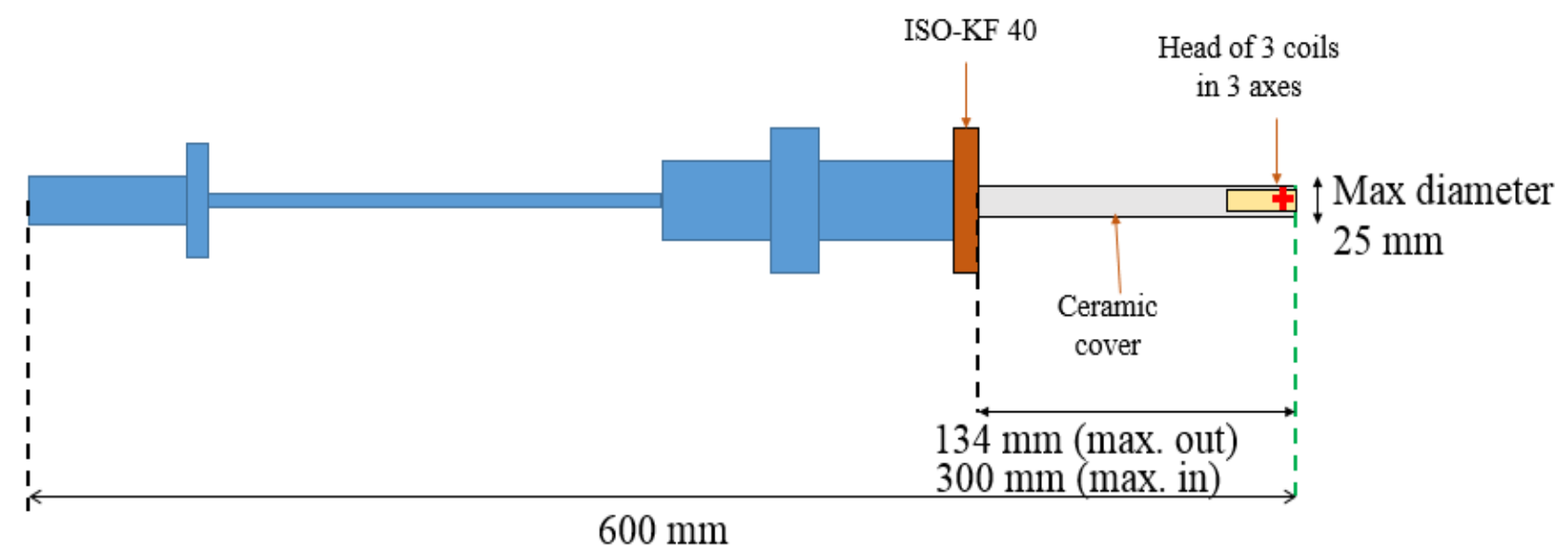

Figure 7: Schematic of the B-dot probe setup. 


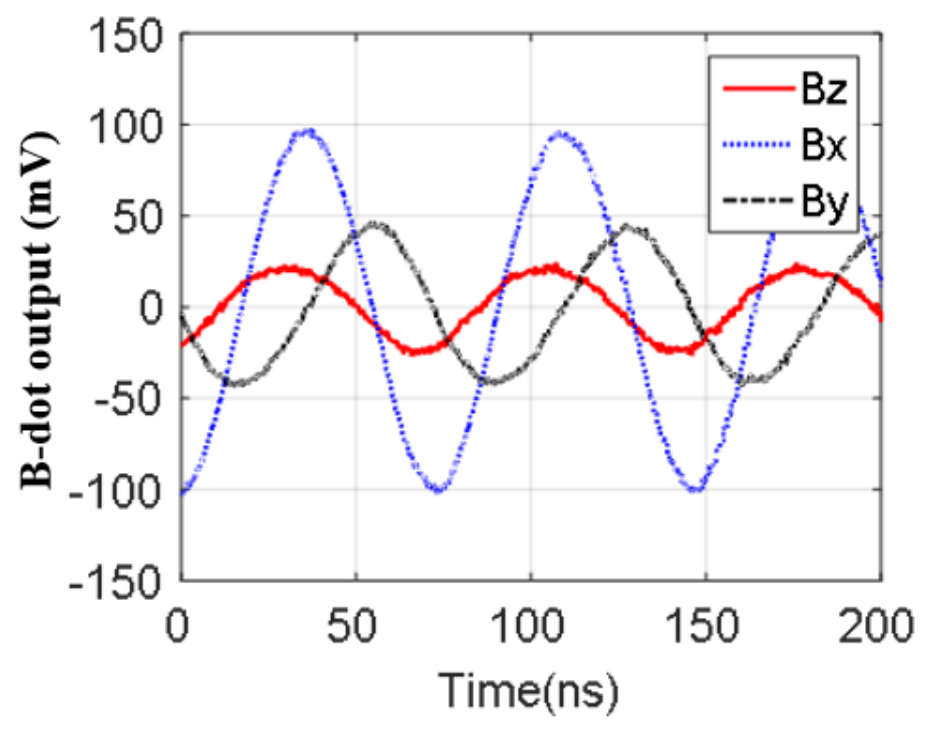

Figure 8: Signal of the B-dot probe measured in the plasma centre at the mid height of the source with a $10 \mathrm{mT}$ magnetic field, $3 \mathrm{~kW}$ of RF power and $0.3 \mathrm{~Pa}$ hydrogen.

\section{Results and discussion}

Figure 9 shows the radial plasma density and temperature profiles at a low magnetic field of 10 $\mathrm{mT}$ ( $3 \mathrm{~kW}$ of RF power and $0.3 \mathrm{~Pa}$ hydrogen) with the end-plates both floating and grounded. The movable Langmuir probe is installed midway along the source $(50 \mathrm{~cm}$ from the helicon exit) in the plane between two coils.

The density profile is nearly a Gaussian distribution, the maximum density at the centre is $1.25 \times 10^{16} \mathrm{~m}^{-3}$ with the floating end-plates. The floating potential of the top end-plate is $-60 \mathrm{~V}$, while it is $-3 \mathrm{~V}$ on the bottom end-plate. With the end-plates grounded, the plasma density is significantly lower $\left(\right.$ ne $\left.7.9 \times 10^{15} \mathrm{~m}^{-3}\right)$.

When the end-plate is floating, the high floating potential indicates the presence of hot electrons and dense plasma between the top end-plate and the antenna. In contrast, with the grounded endplates, the primary (hot) electrons are rapidly lost, and their collision mean-free-path is much longer than $15 \mathrm{~cm}$. On the other hand, the radial plasma temperature profile (see Fig. $9 \mathrm{~b}$ ) is far from expected and measured on the RAID testbed [4].

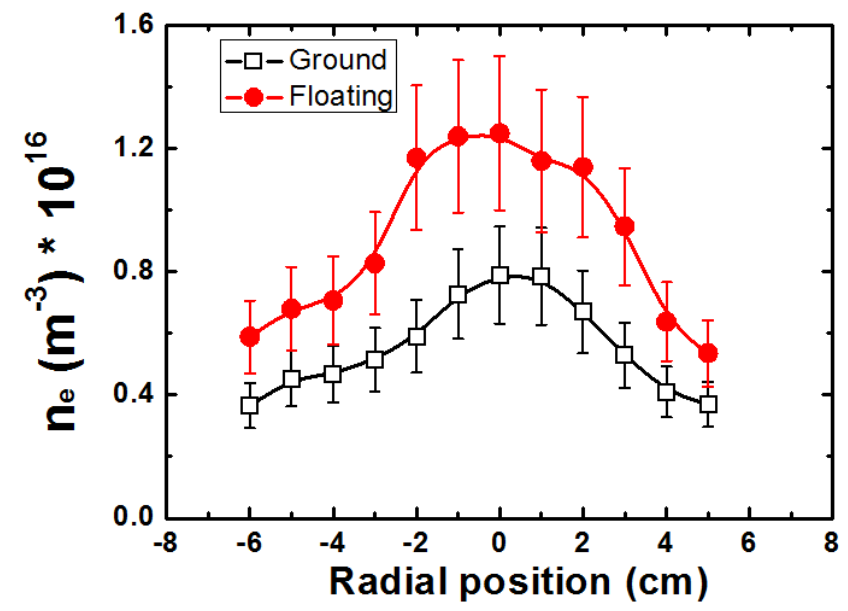

(a)

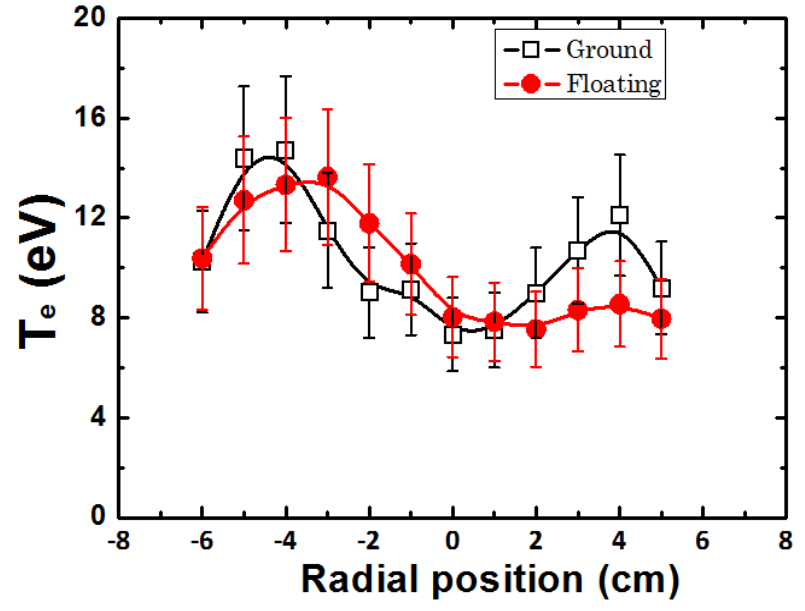

(b)

Figure 9: The radial (a) plasma density and (b) plasma temperature profile of IRFM source with internal coils in both the floating and grounded end-plates with a $10 \mathrm{mT}$ magnetic field, $3 \mathrm{~kW}$ of RF power and 0.3 Pa hydrogen. 
The electron temperature is lower in the plasma centre than on the plasma edges (at radial distance $\sim 3-4 \mathrm{~cm}$ ): $T_{e} \sim 8 \mathrm{eV}$ and $7.3 \mathrm{eV}$ in the centre while it amounts to more than $10 \mathrm{eV}$ on the back and front edges (close to the plasma grid) in the floating and grounded configurations, respectively. The physical process leading to this abnormal electron heating on the edge are not explained at this stage of the experiment. Similar $T_{e}$ ring structure with hot electrons has already been observed by many researchers working in linear magnetized devices [29].

In conjunction with the Langmuir probes, the B-dot probes were installed to diagnose the RF wave, i.e., to measure the wave amplitude and its phase. The wave intensity is measured laterally (left-right) at different heights of the plasma column, i.e., $30 \mathrm{~cm}$ and $50 \mathrm{~cm}$ from the helicon source (see Figure 10). This magnitude probe signal is measured as the root of quadratic sum of the three $x-y-z$ respecting phase components. A clear asymmetry is observed and the wave intensity is two times higher on the right side, despite the correct alignment of the antenna and axial magnetic field.

The B-dot probe has been used to observe the effect of the end-plate polarization. Figure 11 shows the wave amplitude along the central (vertical) axis of the source. Its intensity in the floating configuration is two times higher than with the grounded configuration. The end-plate bias (floating or grounded) only modifies the wave intensity (as observed on figure 11).

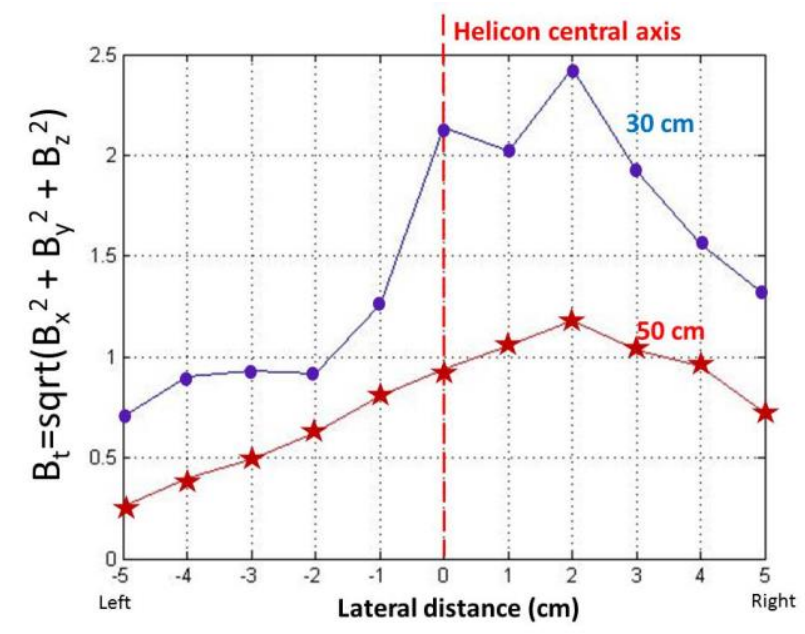

Figure 10: Radial profile of the magnetic field obtained from the B-dot probe at two different distances from the helicon antenna in the floating configuration with $10 \mathrm{mT}$ magnetic field, $3 \mathrm{~kW}$ of RF power and $0.3 \mathrm{~Pa}$ hydrogen.

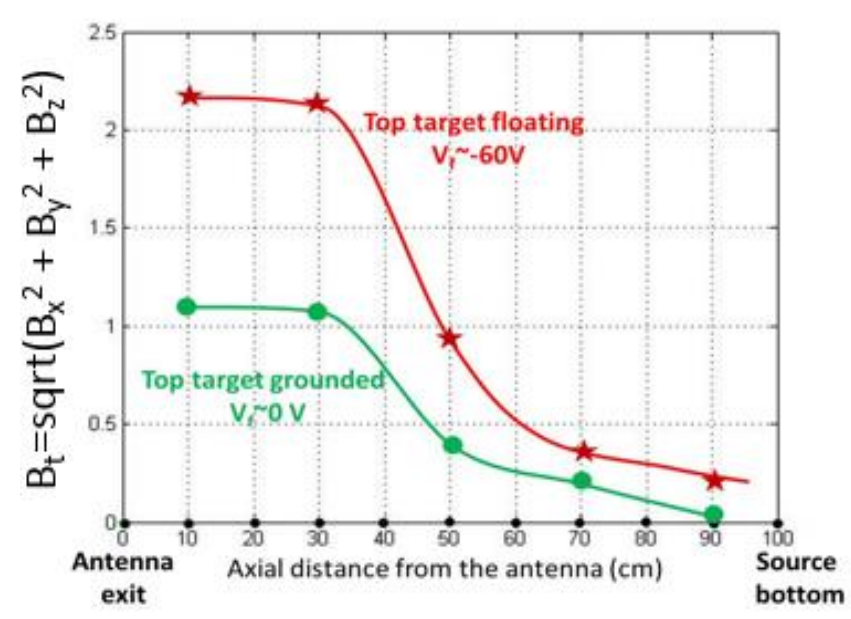

Figure 11: Axial profile of the magnetic field obtained from the B-dot probe placed at center $(\mathrm{r}=0)$ in the floating and grounded configurations with $10 \mathrm{mT}$ magnetic field, $3 \mathrm{~kW}$ of RF power and 0.3 Pa hydrogen.

This observation indicates that a significant amount ( up to 50\%) of the RF power is dissipated in the "stray" plasma formed between the top end-plate and the antenna.

To diminish the propagation of any upstream helicon waves towards the top end-plate and the formation of this stray plasma, a zero magnetic field region above the antenna is suggested.

\subsection{Reverse magnetic field configuration close to the helicon antenna}

The top solenoid in figure 5 is separated into two parts: a direct current flows in the bottom coil (around the antenna) and a reverse current in the top coil (above the antenna). In the antenna region, the direct nominal magnetic field $(\sim 10 \mathrm{mT})$ is maintained, while the zero magnetic field region is located in between the two coils. A simulation of the 3D $10 \mathrm{eV}$ electron trajectories under this magnetic field distribution with the primary velocity oriented upwards (towards the top end-plate) is shown in figure 12. It can be observed from the figure that these electrons are reflected back to the antenna, and they do not reach the top end-plate.

Experimentally, no change in the antenna matching was observed, but a much denser plasma column resulted (see Fig. 13), and the floating potential of the top end-plate was reduced to $-12 \mathrm{~V}$. 


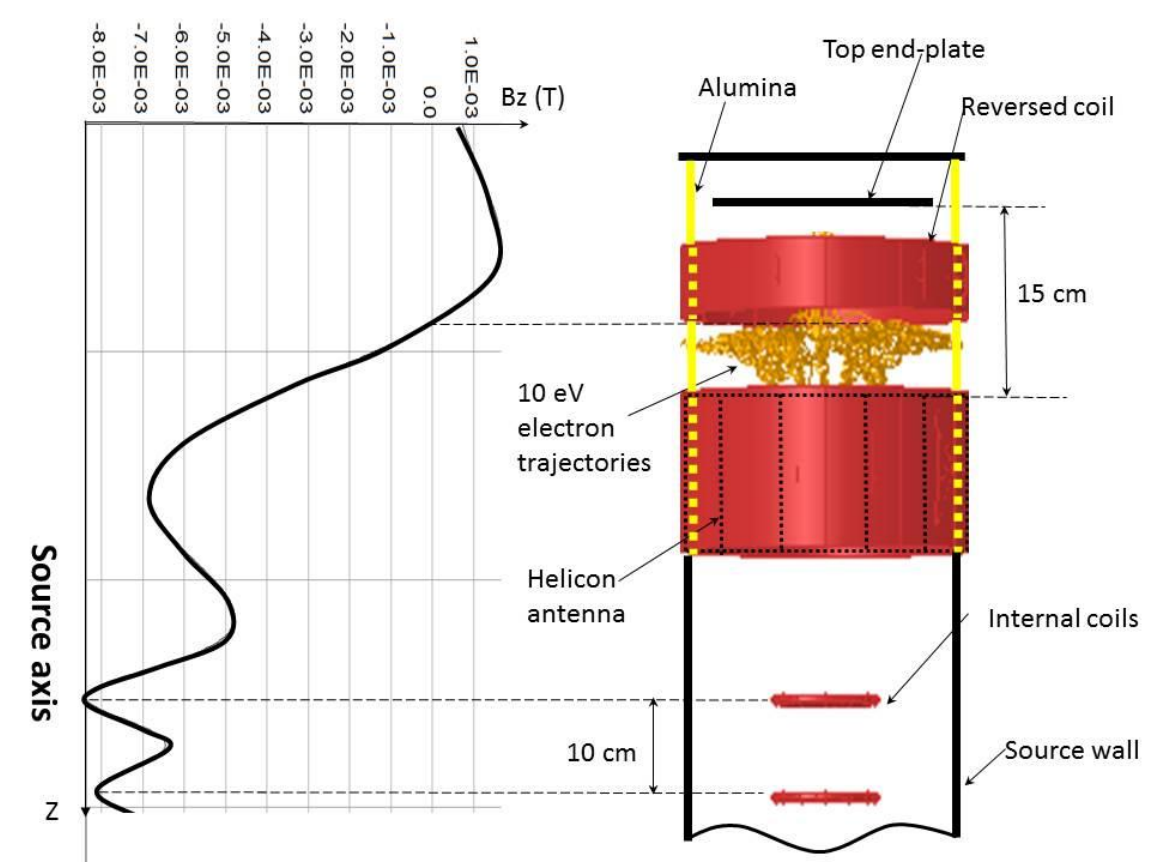

Figure 12: A simulation of the helicon antenna region (Top part of the source) with the reversed field configuration.

Left: axial magnetic field distribution; the dashed line indicates the zero magnetic field region above the antenna.

Right: 3D electron $(10 \mathrm{eV})$ trajectory (yellow lines below the reversed coil) simulation. The electrons are emitted in the antenna region towards the top end-plate; the simulation shows that the electrons are reflected by a mirror effect (in the zero magnetic field region), they cannot attain the top end plate.
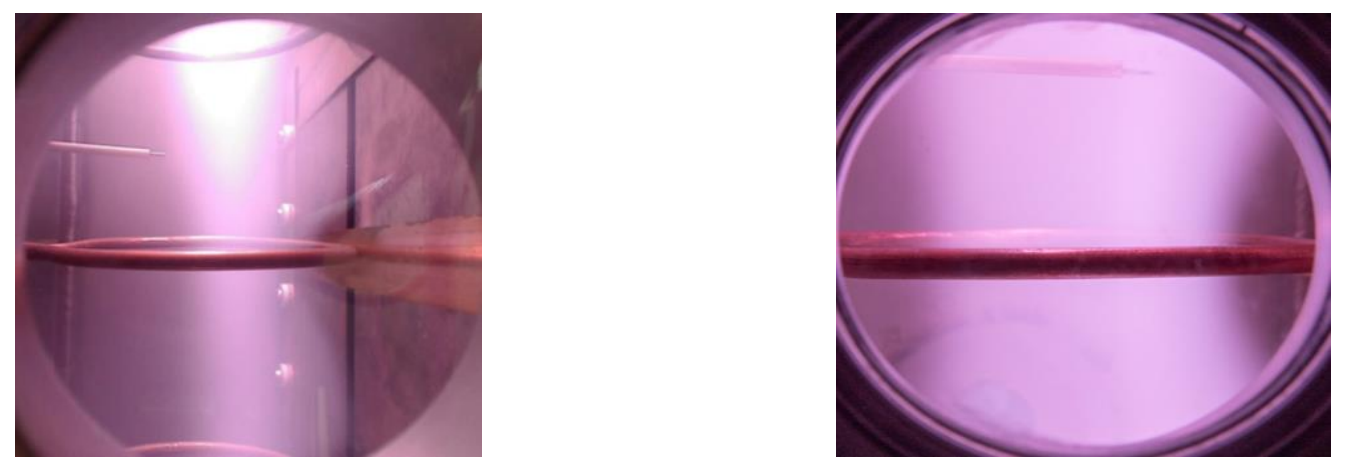

Figure 13: Photographs of the plasma column taken at the mid-height of the plasma column (a) without and (b) with a reverse magnetic field upwards on the helicon antenna in the floating configuration with $10 \mathrm{mT}$ magnetic field, $3 \mathrm{~kW}$ of RF power and $0.3 \mathrm{~Pa}$ hydrogen.

3.1.1 Langmuir probe measurements with reversed configuration: Under the same operating conditions $(\mathrm{B} / /=10 \mathrm{mT}, 3 \mathrm{~kW}$ of $\mathrm{RF}$ power and $0.3 \mathrm{~Pa}$ hydrogen) used to produce figure 9 , the plasma density measured with the Langmuir probes is approximately ten times higher (see Fig. 14). Its profile is more peaked than that in figure 9, and the maximum density is $11.3 \times 10^{16} \mathrm{~m}^{-3}$ in the centre of the plasm column. We also note that the end-plate polarization (floating or grounded) does not change the plasma parameters ( $n e, T e$ ) in contrast to the previous magnetic configuration.

The electron temperature radial profile is significantly lower than that in figure 9, indicating improved confinement of the plasma column. The temperature is lower on the edge, but we still observe the two humps of abnormal and asymmetric electron heating on the edge $(r \sim 3 \mathrm{~cm})$. 
Figure 15 depicts the radial profile of the floating and plasma potential, where we can observe two humps of negative potential on the floating potential corresponding to the hot electron regions. Despite the existence of a significant density gradient between the centre and the edge, the plasma potential is flat $V_{P} \sim 4 \mathrm{~V}$ which is close to the potential of the source walls (at the ground). This flat potential is consistent with the absence of rotating instabilities induced by the $\boldsymbol{E}_{r} \boldsymbol{x} \boldsymbol{B}_{/ /} \mathrm{drift}$ (where $E$ is the radial electric field, $E=0$ ).
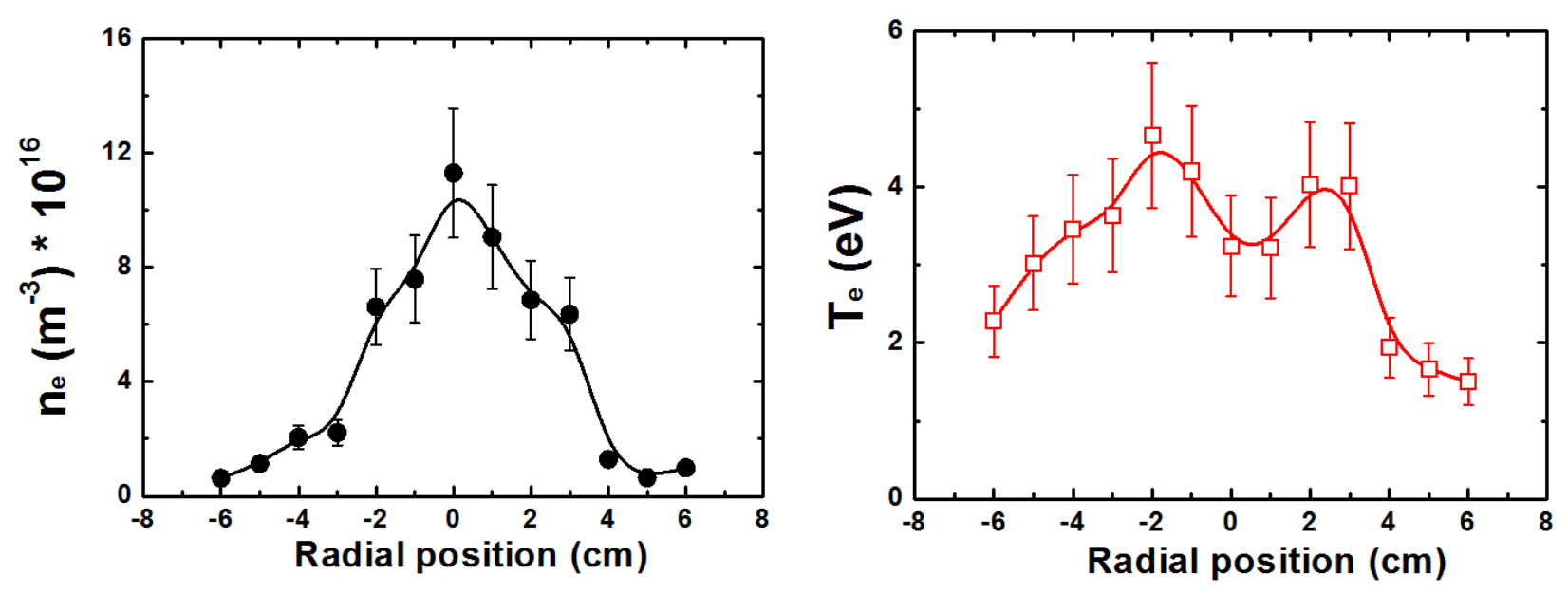

Figure 14: Radial profile of (a) electron density and (b) electron temperature in the reversed field configuration; $\mathrm{B} / /=10 \mathrm{mT}, 3 \mathrm{~kW}$ of $\mathrm{RF}$ power and $0.3 \mathrm{~Pa}$ hydrogen in the floating end-plate configuration.

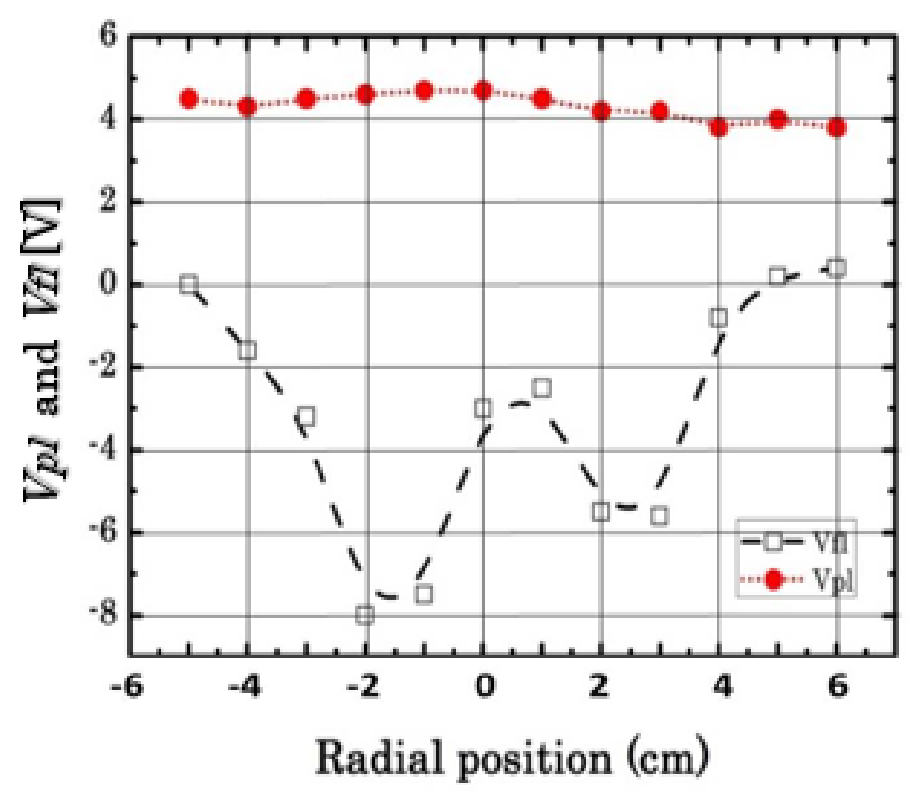

Figure 15: Radial profile of the plasma and floating potential measured with Langmuir probes; $B / /=$ $10 \mathrm{mT}, 3 \mathrm{~kW}$ of RF power and $0.3 \mathrm{~Pa}$ hydrogen at $z=60 \mathrm{~cm}$ in the floating end-plate configuration.

To measure the axial (vertical) distribution of the plasma column, several Langmuir probes were implanted at mid-distance between consecutive coils, at axial distances of $z=40,60,80$ and $100 \mathrm{~cm}$ from the antenna exit. Each probe tip measured the plasma parameters along the central axis of the plasma column $(r=0)$. The antenna operates with $3 \mathrm{~kW}$ of RF power. In figure 16, we observe a linear decrease in the plasma density with the distance from the helicon exit. It can be observed from this figure that the source pressure has a significant effect on the plasma density (a factor two between 0.3 and $0.5 \mathrm{~Pa})$ and on the electron temperature, generating a hotter electron population $\left(T_{e} \sim 10 \mathrm{eV}\right)$ at low pressure $(0.3 \mathrm{~Pa})$. 


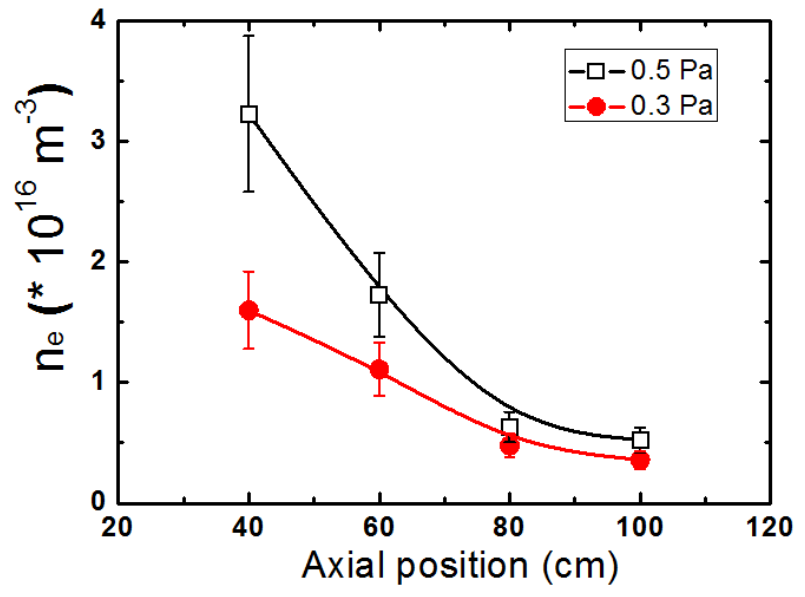

(a)

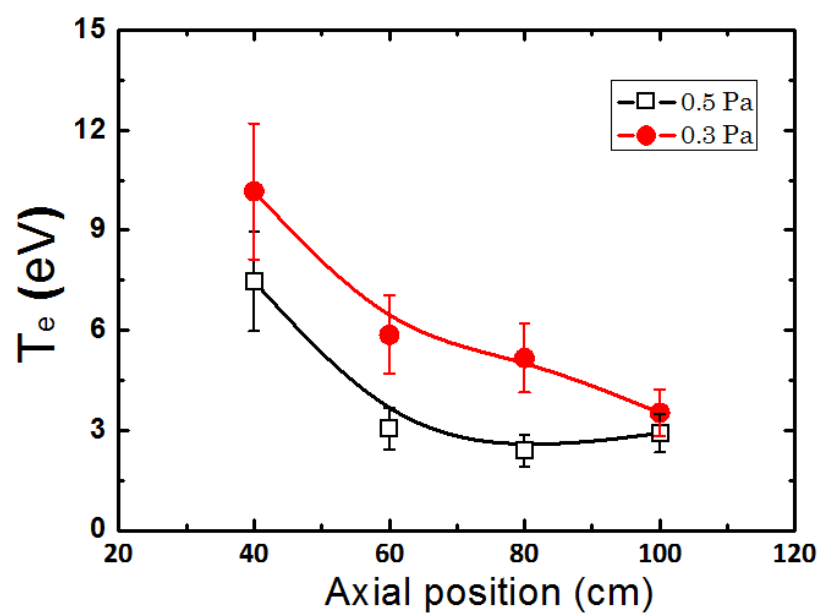

(b)

Figure 16. Vertical (axial) profile of (a) electron density and (b) electron temperature at $0.3 \mathrm{~Pa}$ and $0.5 \mathrm{~Pa}$ hydrogen pressure with a magnetic field of $10 \mathrm{mT}$ and $3 \mathrm{~kW}$ RF power in the floating endplate configuration.

Table 1 compares the plasma parameters in the centre and the edge $(r=4 \mathrm{~cm})$ for the different configurations at $0.3 \mathrm{~Pa}, 3 \mathrm{~kW}$ RF power and $10 \mathrm{mT}$.

Table 1. Comparison of the plasma parameters for different source configurations

\begin{tabular}{c|c|c|c|c}
\hline Configurations & $n_{e}$, centre $\left(\mathrm{m}^{-3}\right)$ & $T_{e}$, centre $(\mathrm{eV})$ & $n_{e}$, edge $\left(\mathrm{m}^{-3}\right)$ & $T_{e}$, edge $(\mathrm{eV})$ \\
\hline Grounded & $7.9 \times 10^{15}$ & 7.3 & $3.7 \times 10^{15}$ & 10.27 \\
\hline Floating & $1.25 \times 10^{16}$ & 8 & $5.9 \times 10^{15}$ & 10.4 \\
\hline Reversed B & $1.13 \times 10^{17}$ & 3.25 & $6.5 \times 10^{15}$ & 2.3 \\
\hline
\end{tabular}

\subsubsection{Effect of the magnetic field intensity on the plasma column parameters}

The source operates in the reversed B configuration with the external solenoid coil around the antenna ( $B_{\text {antenna }}$ or Helicon $\left.B\right)$ and the internal coils in the source volume ( $B_{\text {source }}$ or internal coil $B$ ). To observe the effect of the field intensity within the antenna; $B_{\text {source }}$ is kept constant at $10 \mathrm{mT}$ and

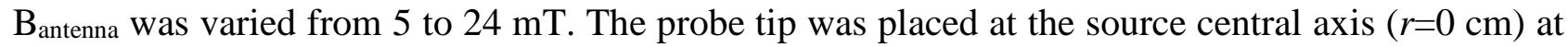
mid-height ( $50 \mathrm{~cm}$ away from the antenna exit). The maximum density was obtained with $\mathrm{B}_{\text {antenna }}=5$ $\mathrm{mT}$; at the lowest intensity, plasma ignition is impossible. We note that above $5 \mathrm{mT}$, the plasma density rapidly drops (see Fig. 17a) while the electron temperature increases (as shown in Fig. 17b).

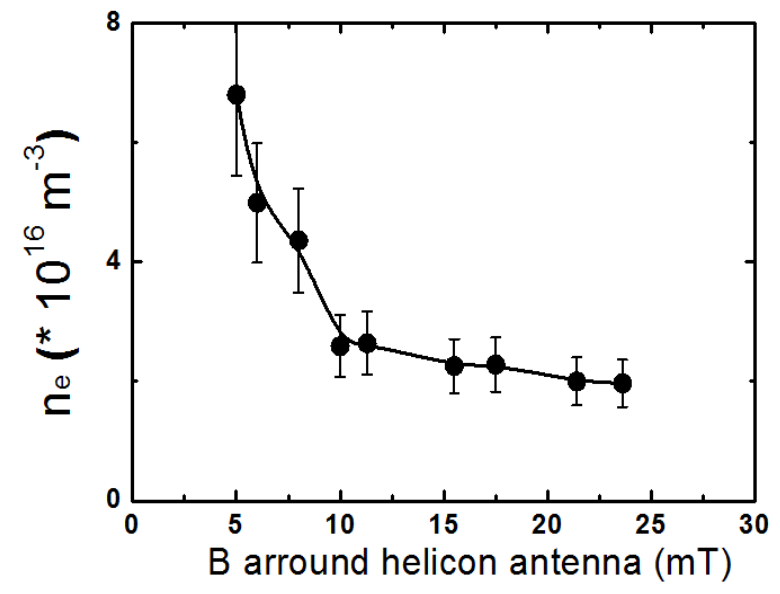

(a)

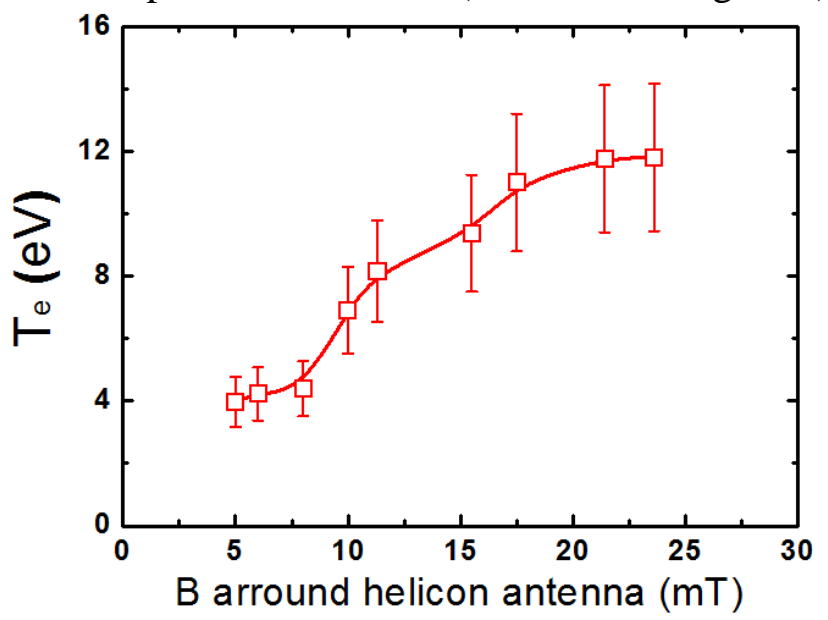

(b)

Figure 17: Electron (a) density and (b) temperature as a function of the magnetic field around the antenna at $1.5 \mathrm{~kW}$ RF power and $0.3 \mathrm{~Pa} \mathrm{H}$ in the floating end-plate configuration. 
Second, keeping $\mathrm{B}_{\text {antenna }}=5 \mathrm{mT}$ (with reversed configuration) and the internal coil current was varied to scan $B_{\text {source }}$ from 10 to $17 \mathrm{mT}$ in the plasma column. Figure $18 \mathrm{a}$ shows that the plasma density increases with the $\mathrm{B}_{\text {source }}$ intensity up to $12 \mathrm{mT}$ and is nearly constant above, while the field intensity has no significant effect on the electron temperature (see Fig. 18.b).

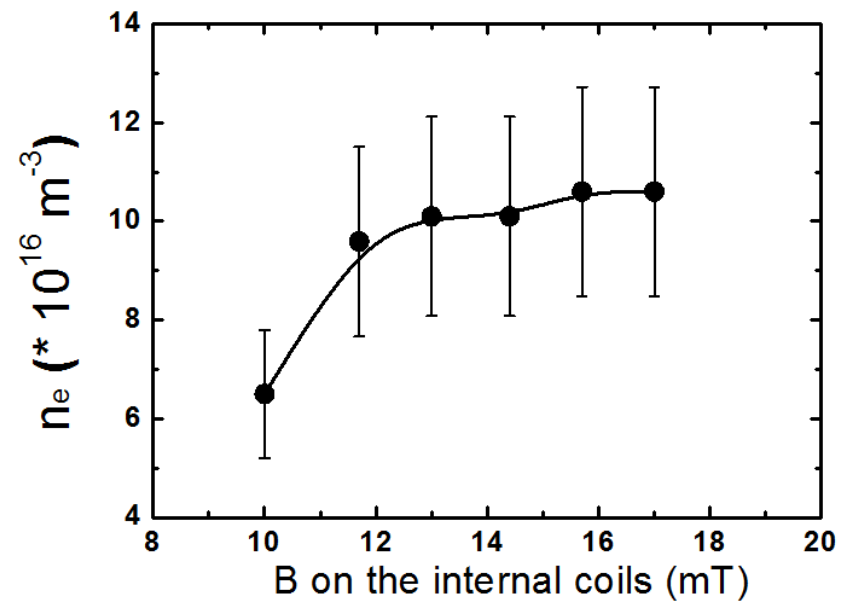

(a)

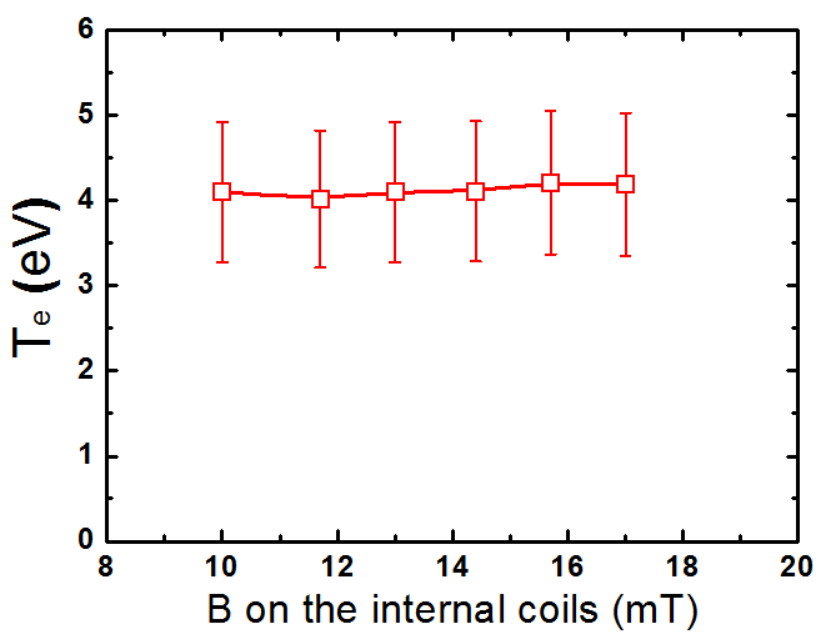

(b)

Figure 18. Electron (a) density and (b) temperature as a function of the magnetic field on the internal coils (the field intensity in the antenna region is kept constant at $5 \mathrm{mT}$ ) at $1.5 \mathrm{~kW}$ RF power and 0.3 $\mathrm{Pa} \mathrm{H}$ in the floating end-plate configuration.

Keeping $\mathrm{B}_{\text {source }}=17 \mathrm{mT}$, a scan $\mathrm{B}_{\text {antenna }}$ shows that $5 \mathrm{mT}$ is still the optimal value, and the plasma

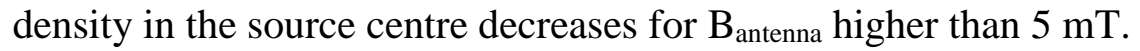

\subsubsection{Reflection of the helicon wave on the top end-plate}

Thus, at present, all of the abovementioned experimental results show that the physical conditions in the antenna region (magnetic field intensity and configurations, the top end-plate polarization) have a major effect on the plasma parameters in the source. Other factors, such as the top end-plate position, its angle and its material (insulator or metal) could play a significant role in wave propagation.

On the RAID testbed, the top end-plate is an insulator (actively cooled ceramic), while on the IRFM source, experiments conducted to data have featured a metal (copper) plate in the plane normal to the helicon axis $15 \mathrm{~cm}$ above the antenna (see Fig. 4).

In the experiments described in the following, the top end-plate was moved step by step towards the antenna level, and the antenna was operated at a reduced RF power $(1.5 \mathrm{~kW})$ to avoid any damage. The source operating conditions were $\mathrm{B}_{\text {antenna }}=5 \mathrm{mT}, \mathrm{B}_{\text {source }}=10 \mathrm{mT}$, and $\mathrm{Ps}=0.3 \mathrm{~Pa}$.

Figures 19 and 20 show the experimental results obtained with the Langmuir and B-dot probes, respectively with the end-plate position close to the top of the antenna $(0 \mathrm{~cm}$ distance between the end-plate and the top of the antenna).

In figure 19, we note that the plasma density profile is symmetric and peaks in the centre (on the helicon axis), $n_{e} \sim 4.5 \times 10^{16} \mathrm{~m}^{-3}$ (the RF power is only $1.5 \mathrm{~kW}$ ), and the electron temperature profile does not exhibit the lateral humps of the electron heating, but we note an asymmetric profile, the temperature being higher on the front (close to the PG) than on the back side of the source.

The lateral (left-right) profile (Fig. 20) of the measured wave B field reveals a quite symmetric profile (red curve) that peaks in the centre while the wave profile with the end-plate at $15 \mathrm{~cm}$ (black curve) is asymmetric and broader. 


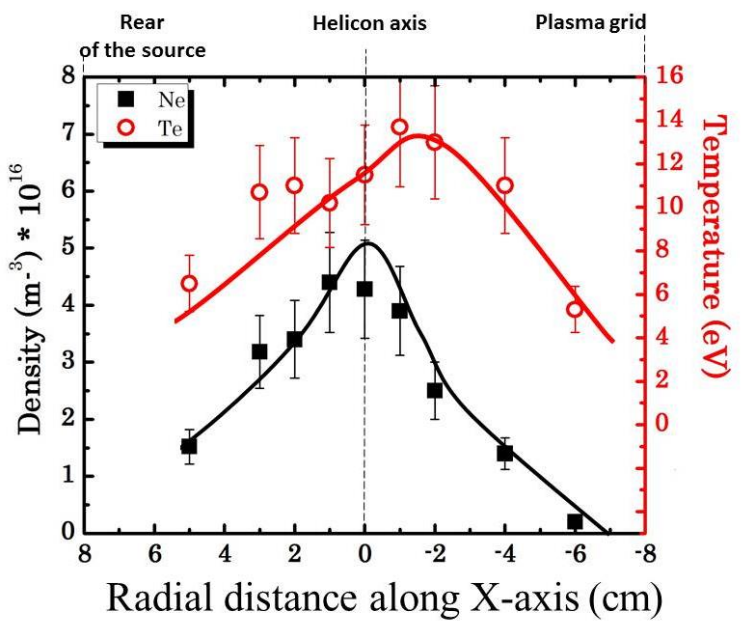

Figure 19: Plasma parameter $\left(n_{e}, T_{e}\right)$ profiles with the Top end-plate position on the antenna level in the mid-height of the plasma column in the floating end-plate configuration with $10 \mathrm{mT}$ magnetic field, $3 \mathrm{~kW}$ of RF power and $0.3 \mathrm{~Pa}$ hydrogen.

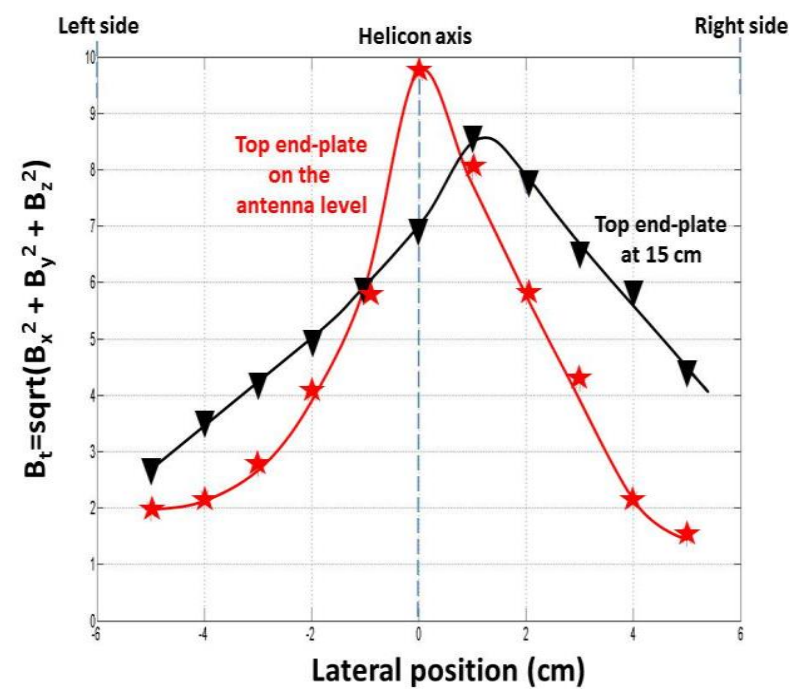

Figure 20: Comparison of the lateral profile of the wave at the antenna exit $(\mathrm{z}=0)$ as a function of the top end-plate position.

The vertical profile of the plasma parameters with the probe tip moving along the helicon central (vertical) axis is depicted in figure 21. The plasma density (black curve) is quite uniform from the antenna exit up to the mid-height of the source, where we can observe a change in the slope. The plasma that expands between two coils (see Fig. 13.b) is probably intercepted at the mid-height by the plasma grid (see Fig. 4).

To overcome this effect, the magnetic field modulation $(\mathrm{B} \perp)$ occurring between the coils must be suppressed. For this purpose, we will implement copper cylinders - instead of the tubes - along the source column.

This experiment will be carried out in the near future.

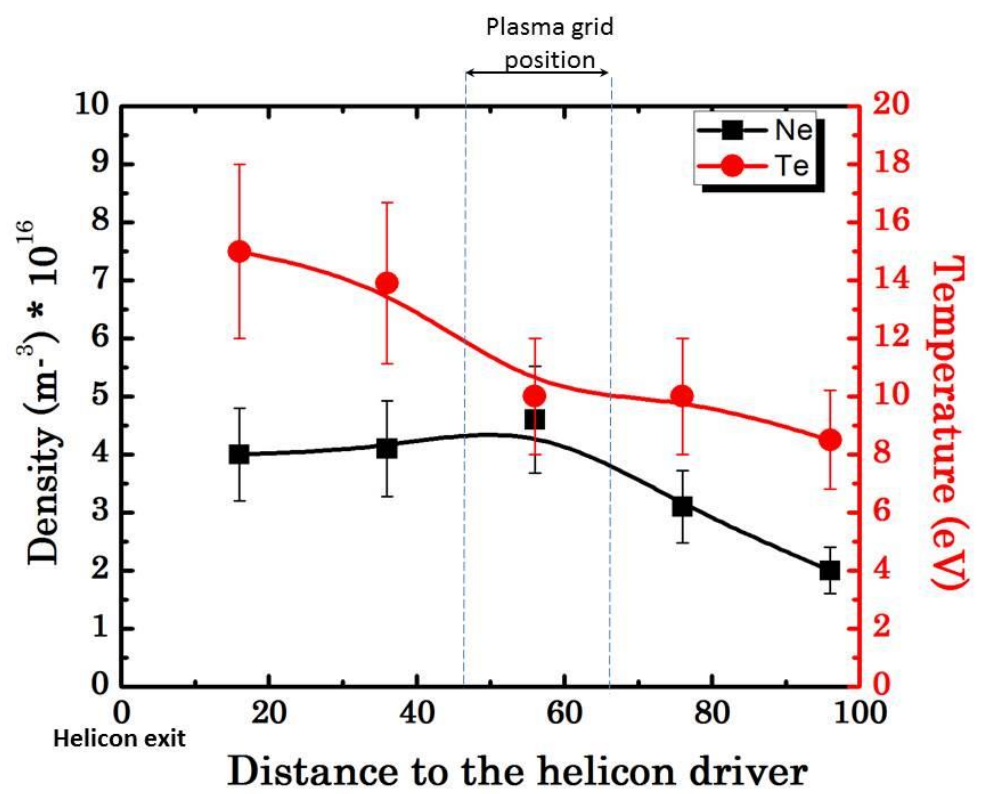

Figure 21: Vertical profile of the plasma density and electron temperature with the probe tip moving along the central helicon axis in the floating end-plate configuration with $10 \mathrm{mT}$ magnetic field, 3 $\mathrm{kW}$ of RF power and $0.3 \mathrm{~Pa}$ hydrogen. 


\subsection{Gas temperature measurement}

The gas diffusion from the source and neutralizer towards the accelerator cavity are the main causes of negative ion losses by stripping. On ITER, despite a high pumping speed $\left(5 \times 10^{6} 1 / \mathrm{s}\right)$, the negative ion losses amount to $28 \%$ with a source filling pressure of $0.3 \mathrm{~Pa}$ [30].

One of the main challenges for future high efficiency NBI systems is to significantly reduce the gas injected within the ion source and the gas neutralizer. The blade-like topology is advantageous because it reduces the gas conductance of the ducts (source and neutralizer), and it eases lateral gas pumping in the accelerator. A thin and long (high) ion source and neutralizer with walls at low temperature (lower than $300{ }^{\circ} \mathrm{K}$ ) would significantly reduce the gas load along the beamline.

A preliminary measurement of the gas temperature of the plasma column (with walls at $300{ }^{\circ} \mathrm{K}$ ) was performed with the assistance of the LPSC and LIPhy laboratories.

The measurement was performed by emission spectroscopy in the domain of the Fulcher- $\alpha$ bands. Q-branches of the Fulcher- $\alpha$ band system $\left(3 \mathrm{p} \pi \mathrm{d}^{3} \Pi_{\mathrm{u}}{ }^{-} \rightarrow 2 \mathrm{~s} \sigma \mathrm{a}^{3} \Sigma_{\mathrm{g}}{ }^{+}\right.$electronic transition) are used in plasma diagnostics, because they are considered to be free of perturbations [30]. A $66 \mathrm{~cm}$ focal monochromator (HRS from JY), equipped with 1200 grooves/mm grating and backed with a CCD camera (EMCCD from Newton Ander, $1600 \times 400$ pixels of $16 \mu \mathrm{m}$ pitch) was used to record highresolution spectra. The instrumental broadening of the optical system, with $50 \mu \mathrm{m}$ entrance slit width, is less than $0.07 \mathrm{~nm}$ FWHM. An optical fiber is installed between the CCD camera and a window on the side of the source (perpendicular to the PG at midway along the source, $50 \mathrm{~cm}$ from the helicon exit). The measurements were done at reversed field around the helicon antenna with $3 \mathrm{~kW}$ of RF power, $0.3 \mathrm{~Pa} \mathrm{H}$ pressure and $10 \mathrm{mT}$ magnetic field in the floating configuration.

The spectrum of the Fulcher- $\alpha$ band around $615 \mathrm{~nm}$ is shown in figure 23 . The $\mathrm{Q}(0-0)$ and $\mathrm{Q}(2-2)$ branches of this spectrum with labelled lines is used for the calculation of rotational temperature. As was discussed in [31-32], both $\mathrm{d}^{3} \Pi_{\mathrm{u}}$ and $\mathrm{a}^{3} \Sigma_{\mathrm{g}}{ }^{+}$states belong to the Hund's case (b) and since their triplet splitting are negligible, the Fulcher- $\alpha$ transition behaves like a ${ }^{1} \Pi_{u^{-}}{ }^{1} \Sigma_{\mathrm{g}}{ }^{+}$transition, with only three $P, Q$ and $R$ branches. It is known from [28-29] that the $\Lambda$-doublet component $\mathrm{d}^{3} \Pi_{\mathrm{u}}{ }^{-}$is free of perturbation and hence the $\mathrm{Q}$ lines originated from it can be used for the determination of the rotational temperature in the $\mathrm{d}^{3} \Pi_{\mathrm{u}}$ state.

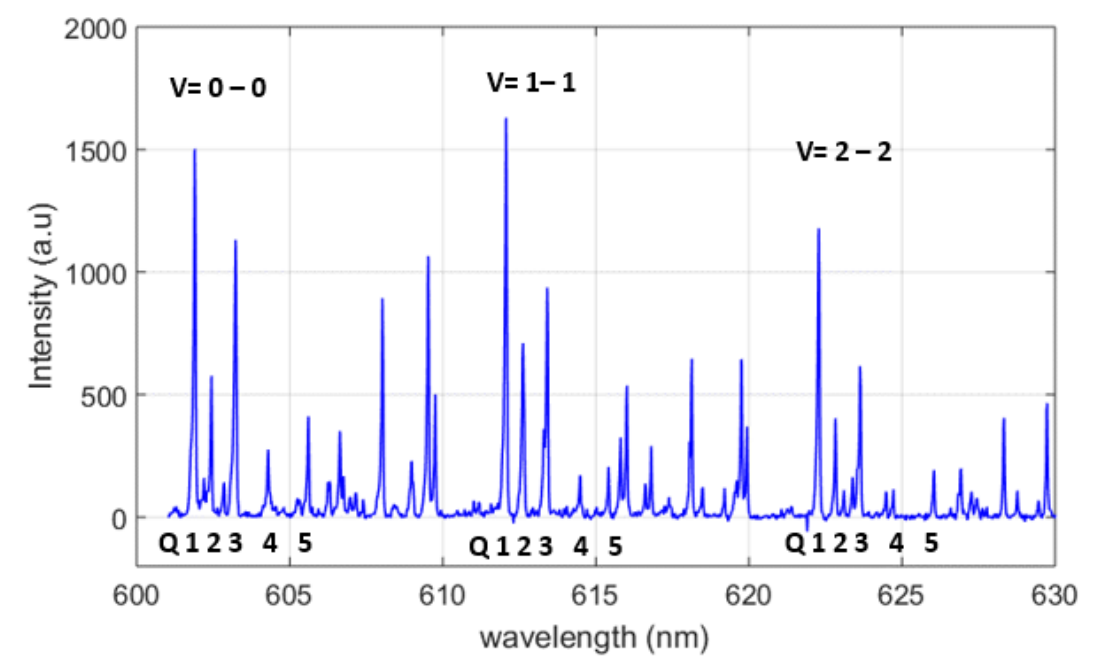

Figure 23: Spectrum of the Fulcher- $\alpha \Delta v=0,1$ and 3 branches with labelled lines used for calculation of rotational temperature. The experimental conditions are $3 \mathrm{~kW}$ of RF power, $0.3 \mathrm{~Pa} \mathrm{H}$ pressure and $10 \mathrm{mT}$ magnetic field in the floating configuration

The rotational temperatures in vibrational levels the $\mathrm{H}_{2}\left(\mathrm{~d}^{3} \Pi_{\mathrm{u}}{ }^{-}\right)$state were determined from the Boltzmann distributions of the $\mathrm{Q}$ branches of rotational transitions of the $v^{\prime}-v^{\prime \prime}=0$ Fulcher- $\alpha$ band. The temperature was calculated using the following formula [33-34]:

$$
I \propto S(2 \Gamma+1) \exp \frac{-B_{v} N(N+1) h c}{k T_{\text {rot }}^{*}}
$$


where $I$ is the line intensity, $S$ is the Hönl-London factor, $\Gamma$ is the total nuclear spin of the rotational level, $B_{v}$ is the molecular rotational constant, $N$ is the rotational quantum number, $h$ is the Planck constant, $c$ is the speed of light, $k$ is the Boltzmann constant and $T^{*}{ }_{r o t}$ is the rotational temperature in the $d$ state. For Q lines, $S=1 / 2(2 N+1)$ and $\Gamma=1$ for the odd $N$ and 0 for the even $N$ value [35]. The value of $T^{*}{ }_{r o t}$ in a vibrational level is obtained from plotting $\ln \left(\frac{I}{S(2 \Gamma+1)}\right)$ for individual lines of its $\mathrm{Q}$ branch, as a function of $N(N+1)$, where $T^{*}$ rot is proportional to $B_{v} h c / k$. The wavelengths of the transitions used are given in table 2 for experimental conditions of $0.3 \mathrm{~Pa} \mathrm{H}_{2}$ pressure, $3 \mathrm{~kW}$ of RF power and internal coil configuration.

Table 2. Wavelengths [31] and relative intensities of $\mathrm{Q}(0-0)$ and $\mathrm{Q}(2-2)$ lines of the Fulcher- $\alpha$ band in experimental conditions of Fig. 23.

\begin{tabular}{c|c|c|c|c|c}
\hline Line & $\mathbf{N}$ & $\boldsymbol{\lambda} \mathbf{Q}(\mathbf{0 - 0}) \mathbf{( n m})$ & $\mathbf{I}_{\text {relative }} \mathbf{Q}(\mathbf{0 - 0})$ & $\boldsymbol{\lambda} \mathbf{Q ( 2 - 2 )}(\mathbf{n m})$ & $\mathbf{I}_{\text {relative} \mathbf{Q}(\mathbf{2}-2)}$ \\
\hline $\mathrm{Q} 1$ & 1 & 601.9 & 1500 & 622.3 & 1180 \\
\hline $\mathrm{Q} 2$ & 2 & 602.4 & 575 & 622.8 & 405 \\
\hline $\mathrm{Q} 3$ & 3 & 603.2 & 1130 & 623.6 & 615 \\
\hline $\mathrm{Q} 4$ & 4 & 604.3 & 275 & 624.7 & 115 \\
\hline Q5 & 5 & 605.6 & 410 & 626 & 195 \\
\hline
\end{tabular}

Now, the rotational temperature $T^{*_{r o t}}$ has to be related to the gas temperature $T_{g}$ but due to the low gas pressure in our experiments, the collision frequency is to low to assume a translation-rotation equilibrium in the $\mathrm{d}^{3} \Pi_{\mathrm{u}}{ }^{-}$state, from which $\mathrm{Q}$ lines are originated. However, it known that when the electron impact excitation from the ground state is the main production source of molecules in the $\mathrm{d}^{3} \Pi_{\mathrm{u}}$ state, the rotational distribution in this later images the rotational distribution of the ground state [34], which corresponds to the conservation of the nuclear rotation momentum of the molecule, or $\Delta N=0$, during the e-impact process $[31,36]$.

As the the ground state $\mathrm{X}^{1} \Sigma_{\mathrm{g}}$ and $\mathrm{d}^{3} \Pi_{\mathrm{u}}$ state have very different rotational constants, thus the rotational temperature of the ground state, $T^{\circ}{ }_{r o t}$, can be deduced from the relation [35]:

$$
T_{\text {rot }}^{0}=\frac{B_{x}}{B_{d}} T_{\text {rot }}^{*}
$$

where $B_{X}=60.85 \mathrm{~cm}^{-1}$ and $B_{d}=30.36 \mathrm{~cm}^{-1}$ are the rotational constants of the ground and $d$ states, respectively. Thanks to the very long lifetime of the molecules in the ground state, the rotationtranslation equilibrium will be established and considering the gas temperature $T_{g}$ equal to $T^{\circ}{ }_{r o t}$ is a good approximation. Figure 24 shows, the evolution of $T^{\circ}$ rot when the RF power was varied from 1.5 $\mathrm{kW}$ up to $4.5 \mathrm{~kW}$ at $0.3 \mathrm{~Pa} \mathrm{H}$ pressure and $10 \mathrm{mT}$ magnetic field on the internal coils in the floating end-plate configuration. The two sets of $T^{\circ}$ rot values reported in this figure correspond to those calculated by Eq. (2) from the rotational temperatures $T^{*}$ rot of $v=0$ and $v=2$ levels of the $d$ state, using the intensities of the $\mathrm{Q}(0-0)$ and $\mathrm{Q}(2-2)$ rotational lines.

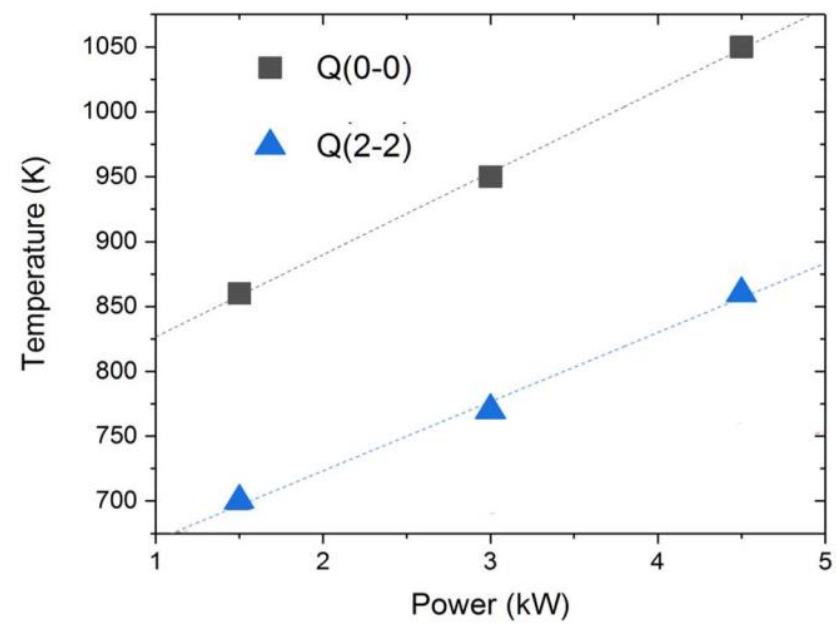

Figure 24: Gas temperature $T_{g}$ evaluated from Q-branches of (0-0) and (2-2) Fulcher bands as a function of the RF power at $0.3 \mathrm{~Pa} \mathrm{H}, 10 \mathrm{mT}$ with floating end-plate. 
We can observe that the evaluated temperatures increase linearly with the RF power. This corresponds to the heating of neutrals (atoms and molecules) by the electron-molecules collisions. We note the same slopes for both $\mathrm{Q}(0-0)$ and $\mathrm{Q}(2-2)$ branches, but the absolute values of the temperature is lower by about $150{ }^{\circ} \mathrm{K}$ when deduced from the $T^{*}$ rot of the $v=2$ level than that from $v=0$ level.

This behavior has been systematically observed in all studies of hydrogen plasmas [31-32, 38-40] and was attributed to the presence of rovibrationally excited hydrogen molecules in the plasma [31]. Briefi et al., [41] consider $\mathrm{Q}(2-2)$ and $\mathrm{Q}(3-3)$ as low distributed states which could be used to determine Trot. The use of $\mathrm{Q}(0-0)$ leads to error but limited at $10 \%$ maximum both for $\mathrm{H}_{2}$ and $\mathrm{D}_{2}$. Iordanova et al., [39] use $\mathrm{Q}(0-0), \mathrm{Q}(1-1)$ and $\mathrm{Q}(2-2)$ to determine $\mathrm{Tg}$ in low pressure $<8 \mathrm{~Pa}$ obtained results are within 20\% error. Qing et al., [32] results for similar measurements show a difference lower than $15 \%$ when three systems are used. Gavara et al., [42] use Q(2-2) system to get Tgas as Bogdanova [43]. Astashkevich et. al, [31] have observed an enhancement of the $T^{*}{ }_{r o t}(0) / T^{*}$ rot $(2)$ ratio with increasing discharge current and attributed it to the increase of the electron density which induces a larger electron-impact excitation of rotational and vibrational levels of the ground state $\mathrm{H}_{2}(\mathrm{X})$ molecules.

These authors have also compared their experimentally measured $T^{*}{ }_{r o t}(0)$ and $T^{*}{ }_{r o t}(2)$ to the population distribution in the rovibronic levels of the $\mathrm{d}^{3} \Pi_{\mathrm{u}}{ }^{-}$state resulting from a computer simulation taking into account different elctron-impact excitation processes. An analysis of the results presented in Fig. 6 of their paper [31] seems to favor the temperature deduced from the measured $T^{*}$ rot $(0)$ to be in close agreement with the assumed gas temperature in the computer simulation, the $T^{*}$ rot $(2)$ value providing a value about $150{ }^{\circ} \mathrm{K}$ lower than the assumed $T_{g}$.

In our case, the error between the results obtained with the $\mathrm{Q}(0-0)$ and $\mathrm{Q}(2-2)$ is close to $20 \%$ which commonly admitted for such measurements.

Finally, it is noted that the measured temperature is in the order of magnitude of the other ICP sources [44].

\section{Conclusions}

This paper reports on the investigation, experimental results and optimization of a "bird-cage" helicon antenna operating with a specific magnetic configuration on the IRFM testbed. The final goal of these developments is to find the magnetic confinement of the plasma source that allows a simultaneous operation of the bird-cage helicon antenna and the extraction of a long (high) blade like negative ion beam from the helicon (magnetized) plasma column. The magnetic confinement studied in this paper is based on a series of current loops $(11 \mathrm{~cm}$ diameter) aligned along the helicon axis within the source (inside the vacuum chamber) which provides the axial magnetic field $(\mathrm{B} / /)$. Each loop consists of a single-turn water-cooled tube in contact with the plasma column and the magnetic field results from a high DC current ( 1000 A) flowing in each tube (coil). To characterize the plasma column and the helicon waves, diagnostics such as Langmuir probes, 3D B-dot probes, and optical emission spectroscopy (OES) with a CCD camera are used. These diagnostics have highlighted several issues of this plasma column. It is apparent that the plasma parameters are different from those on the RAID testbed. For example, we observe plasma and wave asymmetry, and abnormal electron heating on the edges and lower plasma density. It is important to note that the helicon antenna on RAID operates with large external Helmholtz coils $(50 \mathrm{~cm}$ diameter) leading to a more uniform axial magnetic field $(\mathrm{B} / /)$, with negligible lateral components $(\mathrm{B} \perp<1 \mathrm{mT})$ along the plasma column (10 $\mathrm{cm}$ diameter). The B-dot probe on IRFM source has indicated a low plasma density and asymmetry, resulting from the operating conditions of the helicon antenna. Moreover, the measurements have shown that a stray plasma is formed above the antenna by the RF wave propagating in the opposite direction of the source. It has also been observed that the magnetic field 
distribution (reversed configuration), the position and polarization of the metallic end-plate above the antenna play an important role in the downstream plasma parameters. Concerning the gas temperature, we observe a correlation between measured $T_{g}$ and the electron density. This is evidenced for the experimental conditions of figure 24, where the measured $n_{e}$ at the center are 4.5, 11.3 and $14.1 \times 10^{16} \mathrm{~m}^{-3}$ at $1.5,3$ and $4.5 \mathrm{~kW}$ RF power, respectively. In agreement with data reported in table 1 , we also have measured slightly higher $T_{g}$ value when the end-plate was floating than for the grounded condition. Finally, it is shown that when the end-plate is next to the antenna level, the plasma column is more uniform and denser along the source axis, the column's lateral profile is nearly Gaussian and peaks in the centre, the wave profile is symmetric and the abnormal electron heating on the edge disappears. The investigation and optimization of the helicon plasma column will be continued with a set of cylinder coils instead of tubes to suppress the lateral component of the magnetic field

\section{Acknowledgments}

This work has been carried out within the framework of the EUROfusion Consortium and has received funding from the Euratom research and training program 2014-2018 under grant agreement No 633053. The reviews and opinions expressed herein do not necessarily reflect those of the European Commission.

The work of K. M. Ahmed is financially supported by the French and Egyptian governments through a co-financed fellowship granted by the French Embassy in Egypt (Institut Français d'Egypte) and the Science and Technology Development Fund (STDF).

\section{References}

[1] A. Simonin, et al., Nucl. Fusion 55, 123020 (2015).

[2] A. Simonin, et al., "Towards a new generation of high-power high efficiency neutral beam heating system for the future fusion reactors," presented at the $27^{\text {th }}$ IEEE Symposium on Fusion Engineering, Shanghai, China, 4 -8 June 2017.

[3] W. Chaibi, et al., AIP conference proceedings, ISBN 978-0-7354-0630-8, pp. 385 (2009).

[4] I. Furno et al., EPJ Web Conf. 157, 03014 (2017).

[5] P. Guittienne, E. Chevalier and Ch. Hollenstein, Journal of Applied Physics 98, 083304 (2005).

[6] K. Choe et al., Rev. Sci. Instrum. 85(2), 02B318 (2014).

[7] S. H. Han, "Development of a novel large-area high-density uniform plasma source with multiple helicon plasma injectors", PhD thesis, Seoul National University, (2004).

[8] Y. J. Kim, S. H. Han, W. Hwang, and Y. S. Hwang, Thin Solid Films 435, 270 (2003).

[9] F. F. Chen, J. D. Evans, and G. R. Tynan, Plasma Sources Sci. Technol. 10, 236 (2001).

[10] J. F. Caneses, B. D. Blackwell, and P. Piotrowicz, Physics of Plasmas 24, 113513 (2017).

[11] J. Rapp et al., IEEE Trans. Plasma Sci. 44(12), 3456-3464 (2016).

[12] J. B. O. Caughman et al., J. Vac. Sci. Technol. Vac. Surf. Films, 35(3), 03E114(2017).

[13] C. Charles, Appl. Phys. Lett. 84, 332 (2004).

[14] J. P. Squire et al., Thin Solid Films 506-507, 579 (2006).

[15] F. R. Chang-Diaz, Thin Solid Films 506-507, 449 (2006).

[16] T. Nakamura, et al., International Scholarly and Scientific Research \& Innovation 6(11): 14981502 (2012).

[17] T. Ishii, et al., JPS Conf. Proc. 1, 015047 (2014).

[18] S. Shinohara, et al., Physics of Plasma 16, 057104 (2009)

[19] A Pandey et al Plasma Phys. Control. Fusion 61065003 (2019).

[20] T.-T. Miao, et., Review of Scientific Instruments 81, 02B105 (2010).

[21] S. Briefi and U. Fantz, AIP Conf. Proc. 1515, 278 (2013).

[22] J. Santoso, R. Manoharan, S. O’Byrne, and C. S. Corr, Phys. Plasmas 22, 093513 (2015).

[23] C. Marini, et al., Nucl. Fusion 57, 036024 (2017).

[24] B Heinemann et. al, New J. Phys. 19015001 (2017).

[25] Bandyopadhyay et al., IEEE Trans. Plasma Sci. 42(3):624-627 (2014). 
[26] I Morgal, "Characterization of the Helicon Plasma Generated Inside the Cybele Negative Ion Source with Different Magnetic Field Configurations", to be published.

[27] OPERA software by COBHAM plc. Available: https://operafea.com/

[28] R. Jacquier et al., 30th edition of Symposium on fusion technology (SOFT 2018), Giardini Naxos (Messina, Sicily), 16-21 Sept. 2018.

[29] S. K. Karkari , S. K. Mishra, and P. K. Kaw Phys. Plasmas 22, 092107 (2015).

[30] A. Simonin, et al., New J. Phys. 18: 125005 (2016).

[31] S. A. Astashkevich, et al., J. Quant. Specfrosc. Radial. Transfir Vol. 56, No. 5, pp. 725-751. 1996.

[32] Z. Qing, D.K. Otorbaev, G.J.H. Brussard, M.C.M. van de Sanden and D.C. Schram, J. Appl. Phys. 80 (1996) 1312

[33] H. M. Crosswhite, "The hydrogen molecule wavelength tables of Gerhard Heinrich Dieke", Wiley-Interscience, Division of John Wiley \& Sons, Inc., New York, 1972, 616.M.

[34] M. Anguš, et al., "Actinometric Study of RF Hydrogen Discharge at $13.56 \mathrm{MHz}$ and $27 \mathrm{MHz}$,, in WDS'12 Proceedings of Contributed Papers: Part II - Physics of Plasmas and Ionized Media (eds. J. Safrankova and J. Pavlu), Prague, Matfyzpress, pp. 105-110, 2012.

[35] I. Kowacs, Rotational structure in the Spectra of Diatomic Molecules (Adam Hilger, London, 1966)

[36] P. Bruggman, N. Sadeghi, DC Schram and V. Linss, Plasma Sources Sci. Technol. 23, 023001 (2014).

[37] H.P. Huber and G. Herzberg, Molecular Spectra and Molecular Structure. IV. Constants of Diatomic Molecules (Van Norstrand, New York 1972).

[38] G. Lj. Majstorovic, N.M. Sisovic and N. Konjevic, Plasma Sources Sci. Technol. 16, 750 (2007).

[39] S. Iordanova, Journal of Physics: Conference Series 113012005 (2008)

[40] J-J. Dang, K-J. Chung and Y.S. Hwang, Rev. Sci. Instrum. 87 (2016) 053503

[41] S. Briefi, D. Rauner and U. Fantz, J. Quant. Specfrosc. Radial. Transfir 187, 135-144 (2017).

[42] Z. Gavare, G. Revalde and A. Skudra International journal of spectroscopy 2010, 804506 (2010).

[43] I. P. Bogdanova, G. V. Efremova, B. P. Lavrov, V. N. Ustimov and V. I. Yakovleva, Opt. Spectropic 50, 63 (1981).

[44] U. Fantz and D. Wünderlich, New J. Phys. 8, 301- (2006). 